BNL-112633-2016-JA

\title{
Inverse Oxide/Metal Catalysts in Fundamental Studies and Practical Applications: A Perspective of Recent Developments
}

José A. Rodriguez, Ping Liu, Jesús Graciani, Sanjaya D. Senanayake, David C. Grinter, Dario Stacchiola, Jan Hrbek, and Javier Fernández-Sanz

Submitted to Journal of Physical Chemistry Letters

July 2016

Chemistry Department

Brookhaven National Laboratory

\author{
U.S. Department of Energy \\ USDOE Office of Science (SC), \\ Basic Energy Sciences (BES) (SC-22)
}

Notice: This manuscript has been authored by employees of Brookhaven Science Associates, LLC under Contract No. DE- SC0012704 with the U.S. Department of Energy. The publisher by accepting the manuscript for publication acknowledges that the United States Government retains a non-exclusive, paid-up, irrevocable, world-wide license to publish or reproduce the published form of this manuscript, or allow others to do so, for United States Government purposes. 


\section{DISCLAIMER}

This report was prepared as an account of work sponsored by an agency of the United States Government. Neither the United States Government nor any agency thereof, nor any of their employees, nor any of their contractors, subcontractors, or their employees, makes any warranty, express or implied, or assumes any legal liability or responsibility for the accuracy, completeness, or any third party's use or the results of such use of any information, apparatus, product, or process disclosed, or represents that its use would not infringe privately owned rights. Reference herein to any specific commercial product, process, or service by trade name, trademark, manufacturer, or otherwise, does not necessarily constitute or imply its endorsement, recommendation, or favoring by the United States Government or any agency thereof or its contractors or subcontractors. The views and opinions of authors expressed herein do not necessarily state or reflect those of the United States Government or any agency thereof. 


\section{Inverse Oxide/Metal Catalysts in Fundamental Studies and Practical Applications: A Perspective of Recent Developments}

José A. Rodriguez, ${ }^{*}$ a,b Ping Liu, ${ }^{\text {a,b }}$ Jesús Graciani, ${ }^{c}$ Sanjaya D. Senanayake, ${ }^{a}$ David C. Grinter, ${ }^{\text {a }}$ Dario Stacchiola, ${ }^{\mathrm{a}}$ Jan Hrbek, ${ }^{\mathrm{a}}$ and Javier Fernández-Sanz ${ }^{\mathrm{c}}$

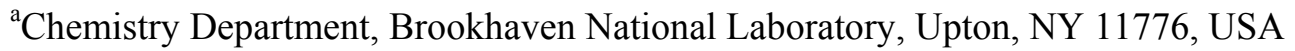

${ }^{b}$ Department of Chemistry, State University of New York (SUNY), Stony Brook, NY 11749, USA

${ }^{\mathrm{c}}$ Departamento de Química Física, Universidad de Sevilla, Sevilla 41012, Spain

*Corresponding author. E-mail : rodrigez@bnl.gov 


\section{Abstract}

Inverse oxide/metal catalysts have shown to be excellent systems for studying the role of the oxide and oxide-metal interface in catalytic reactions. These systems can have special structural and catalytic properties due to strong oxide-metal interactions difficult to attain when depositing a metal on a regular oxide support. Oxide phases which are not seen or are metastable in a bulk oxide can become stable in an oxide/metal system opening the possibility for new chemical properties. Using these systems it has been possible to explore fundamental properties of the metal-oxide interface (composition, structure, electronic state) which determine catalytic performance in the oxidation of $\mathrm{CO}$, the water-gas shift and the hydrogenation of $\mathrm{CO}_{2}$ to methanol. Recently, there has been a significant advance in the preparation of oxide/metal catalysts for technical or industrial applications. One goal is to identify methods able to control in a precise way the size of the deposited oxide particles and their structure on the metal substrate.

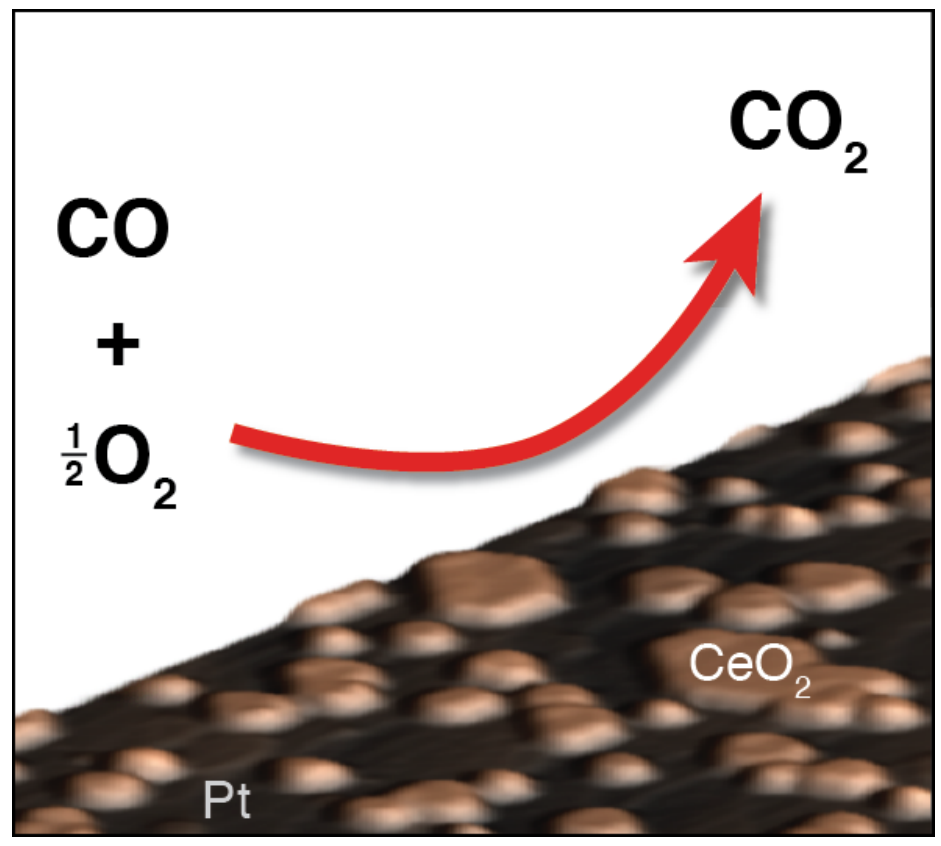


Catalysis is a key enabling technology in our modern world. More than $80 \%$ of all our chemicals and materials are generated in industrial processes which involve the use of catalysis at one stage or another. Most industrial catalysts contain a combination of metals and oxides. ${ }^{1,2,3}$ In the traditional methodology for the preparation of these catalysts, a small amount of a metal is dispersed on an oxide support. ${ }^{1,3}$ In these systems, the oxide phase can act as a simple template for the dispersion of the metal phase or it can be a direct participant in the catalytic process. $^{2}$ When the oxide is involved in the catalysis, there is a motivation to revamp the traditional configuration of industrial catalysts (Figure 1) to exploit the intrinsic properties of metal oxides and obtain a superior performance. ${ }^{4,5,6,7}$ In principle, oxide nanoparticles can have special electronic and chemical properties as a consequence of their limited size and a high density of defects and corner or edge surface sites. ${ }^{8}$ Catalysts generated by the deposition of oxide particles on a metal substrate have been studied for a long time. ${ }^{9,10}$ Originally, Georg-Maria Schwab proposed the use of this catalyst configuration to study metal-support interactions ${ }^{9}$ and many others scientists have followed this suggestion. ${ }^{10,11,12}$ When a reactant interacts with an inverse oxide/metal catalyst, it can bind to regular centers and imperfections of the oxide particle, pure metal centers, and the metal-oxide interface. Over the years it has been found that well-defined inverse oxide/metal catalyst can have special properties, ${ }^{10,11,13,14,15,16,17,18}$ a fact that has motivated recent efforts to prepare this type of system in forms which are suitable for technical applications. ${ }^{6,719,20}$ Furthermore, recent studies using high-resolution transmission electron microscopy (HRTEM) have detected overlayers of $\mathrm{ZnO}_{\mathrm{x}}$ on top of the $\mathrm{Cu}$ particles present in copper/zinc oxide catalysts used for the synthesis of methanol, $\mathrm{CH}_{3} \mathrm{OH}$ (Figure 2). ${ }^{21,22}$ In these catalysts, the active phase probably has an inverse oxide/metal configuration. ${ }^{21,22}$ The same is valid in $\mathrm{Cu} / \mathrm{MoO}_{\mathrm{x}}, \mathrm{Rh} / \mathrm{TiO}_{2}, \mathrm{Ni} / \mathrm{CeO}_{2}, \mathrm{Pt} / \mathrm{CeO}_{\mathrm{x}}$ and $\mathrm{Pt} / \mathrm{TiO}_{2}$ catalysts activated by pre-treatment 
(reduction) in hydrogen..$^{9,11,12,23,24,25,26}$ Oxides that have a low surface free energy exhibit a tendency to cover metals upon partial reduction. Thus, an oxide/metal configuration maybe more common in heterogeneous catalysts than expected. ${ }^{9,21,22,26,27}$ For all of these reasons, in this article we present a perspective on the use of inverse oxide/metal catalysts in fundamental studies and practical applications.

An understanding of the behavior of inverse oxide/metal catalysts requires a fundamental knowledge of their structural and electronic properties. In the area of conventional metal/oxide catalysts, a lot of research has been aimed at understanding the effects of strong metal-support interactions (SMSIs) on the structural, electronic and chemical properties of the supported metal..$^{1,3,9,11,27}$ In an inverse oxide/metal catalyst there can be substantial perturbations in the physical and chemical properties of the oxide phase. ${ }^{10,18,28}$ In Figure 2, the overlayer of zinc oxide on top of the copper particles has a graphitic structure which is different from the stable wurtzite structure typically seen for bulk $\mathrm{ZnO} .^{21}$ This perturbation in the structure of the oxide is a consequence of a strong oxide-metal interaction (SOMI) $)^{21,22}$ and is a common phenomenon in inverse oxide/metal catalysts. ${ }^{28,29,30,31,32}$ Moving from the results in Figure 2 for a powder system to studies with well-defined oxide/metal catalysts, one finds that overlayers of $\mathrm{ZnO}$ deposited on $\mathrm{Cu}(111)$ and $\operatorname{Pt}(111)$ are structurally perturbed ${ }^{13,33}$ and have special catalytic properties for the oxidation of $\mathrm{CO}$ (Figure 3) and the conversion of $\mathrm{CO}_{2}$ into methanol. ${ }^{13,33,34}$

A large number of articles have appeared in the literature examining the growth of alumina, silica, magnesium oxide, titania, iron oxide, cobalt oxide, nickel oxide, zinc oxide, molybdenum oxide, terbia, samaria, ceria and zirconia on well-defined metal substrates. $^{10,13,14,15,18,26-30,35 \text {, }}$ For several systems, studies using scanning tunneling microscopy (STM) and low-energy electron diffraction (LEED) have shown structures and compositions for 
the supported oxides which are different from those seen in bulk phases. ${ }^{12,18,27-30,35}$ This is usually a consequence of SOMIs. Inverse oxide/metal systems which contain $\mathrm{FeO}_{\mathrm{x}}, \mathrm{CeO}_{\mathrm{x}}, \mathrm{TiO}_{\mathrm{x}}$ and $\mathrm{MgO}$ overlayers have been the subject of many studies ${ }^{10-16,28,32,34,36,37}$ and deserve special attention. In the next paragraphs, we will describe studies which illustrate the special behavior of these systems and how they can be useful to explore fundamental properties of the metal-oxide interface (composition, structure, electronic state) which determine catalytic performance.

Iron oxide forms compounds with different oxidation states and crystal structures. ${ }^{31,32}$ The $\mathrm{Fe}^{2+}$ and $\mathrm{Fe}^{3+}$ cations have distinctive chemical properties. Figure 4 shows STM images for overlayers of $\mathrm{FeO}_{\mathrm{x}}$ on a $\mathrm{Au}(111)$ surface. $^{32}$ Depending on the mode of preparation, ${ }^{32,36,37}$ one can have overlayers of $\mathrm{FeO}, \mathrm{Fe}_{3} \mathrm{O}_{4}$ or $\mathrm{Fe}_{2} \mathrm{O}_{3}$ on the gold substrate. $\mathrm{FeO}$ consists of a $\mathrm{Fe}-\mathrm{O}$ bilayer, which grows epitaxially on the gold substrate and exhibits a $\mathrm{FeO}(111)$ termination. Under oxidative conditions, the lattice of $\mathrm{FeO}_{\mathrm{x}}$ always has a hexagonal (111)-like periodicity but its height evolves from monolayer $\mathrm{FeO}(111)$ to multilayer $\mathrm{Fe}_{3} \mathrm{O}_{4}(111)$ and $\mathrm{Fe}_{2} \mathrm{O}_{3}(001)$. ${ }^{32,36,37}$ Each one of these overlayers has different electronic properties. The $\mathrm{FeO}(111)$ and $\mathrm{Fe}_{3} \mathrm{O}_{4}(111)$ structures are a direct consequence of a quite interesting SOMI. ${ }^{32}$ These structures do not exist as stable bulk oxides but they can exist in the inverse oxide/metal catalysts even under CO oxidation conditions (Figure 5). ${ }^{32}$ The $\mathrm{Fe}^{2+}$ sites present in $\mathrm{FeO}(111) / \mathrm{Au}(111)$ and $\mathrm{Fe}_{3} \mathrm{O}_{4}(111) / \mathrm{Au}(111)$ are active for the adsorption and dissociation of $\mathrm{O}_{2}$. Unfortunately, the overlayer of $\mathrm{FeO}$ is too reactive and part of it transforms into $\mathrm{Fe}_{3} \mathrm{O}_{4}$ and $\mathrm{FeC}_{\mathrm{x}}$. The accumulation of $\mathrm{FeC}_{\mathrm{x}}$ deactivates the catalyst. ${ }^{16,32}$ In this respect, $\mathrm{Fe}_{3} \mathrm{O}_{4}(111) / \mathrm{Au}(111)$ seems as a better choice as a catalyst. It has stable and enough $\mathrm{Fe}^{2+}$ sites to yield very good catalytic activity and does not get poisoned by carbon or carbide species. In fact, the SOMI between $\mathrm{Fe}_{3} \mathrm{O}_{4}(111)$ and $\mathrm{Au}(111)$ makes this iron oxide an excellent catalyst for the oxidation of $\mathrm{CO} .^{16,32}$ 
The chemical nature of the metal substrate can have a strong effect on the relative stability of an oxide overlayer. ${ }^{31,38,39}$ Figure 6 compares the calculated stability of $\mathrm{Fe}_{10} \mathrm{O}_{6}$ and $\mathrm{Fe}_{10} \mathrm{O}_{18}$ clusters on $\mathrm{Au}(111)$ and $\mathrm{Pt}(111) .^{31}$ The $\mathrm{Fe}_{10} \mathrm{O}_{6}$ cluster is deficient in oxygen and it can be stabilized by interaction with a metal substrate. For this $\mathrm{Fe}_{10} \mathrm{O}_{6}$ cluster the binding energy calculated on $\operatorname{Pt}(111)$ is $0.53 \mathrm{eV}$ larger than on $\mathrm{Au}(111)$. For the oxidation of the oxide overlayer, $\mathrm{Fe}_{10} \mathrm{O}_{6} / \mathrm{M}(111)+6 \mathrm{O}_{2} \rightarrow \mathrm{Fe}_{10} \mathrm{O}_{18} / \mathrm{M}(111)$, the calculated reaction energy $(\Delta \mathrm{G})$ on $\mathrm{Pt}(111)$ was $-1.08 \mathrm{eV}$ versus $-1.44 \mathrm{eV}$ on $\mathrm{Au}(111)$ with a larger activation barrier on the platinum substrate. ${ }^{31}$ Thus, metastable islands of iron oxide will be more stable on $\operatorname{Pt}(111)$ than on $\mathrm{Au}(111)$ opening interesting opportunities for applications in catalysis. ${ }^{31,40}$ Indeed, the addition of an overlayer of $\mathrm{FeO}(111)$ to $\mathrm{Pt}(111)$ leads to a very large increase in the activity for $\mathrm{CO}$ oxidation. ${ }^{40}$ In an $\mathrm{O}_{2}$-rich $(\mathrm{CO}: \mathrm{O}$ ratio of $1: 5)$ reaction environment, the $\mathrm{FeO}(111)$ overlayer adsorbed oxygen while maintaining its long-range order and catalytic activity. On the other hand, under a $\mathrm{CO}$-rich (CO:O ratio of 1:5) reaction environment, the $\mathrm{FeO}(111)$ overlayer underwent dewetting that led to deactivation of the catalyst. ${ }^{40}$

Ceria is an oxide widely used in catalysis due to its ability to change between $4+$ and $3+$ oxidation states. ${ }^{41}$ Inverse oxide/metal catalysts have been generated by depositing ceria particles on surfaces of $\mathrm{Rh},{ }^{18,42,43} \mathrm{Ru},{ }^{42,44,45} \mathrm{Ni},{ }^{46} \mathrm{Pd},{ }^{47} \mathrm{Pt},{ }^{12,30,48,49,50} \mathrm{Cu},{ }^{51,52,53} \mathrm{Re}^{54}$ and $\mathrm{Au} .{ }^{14,55,56} \mathrm{At}$ small coverages of ceria on the metals, the growth mode and morphology of the ceria nanoparticles changes drastically depending on the preparation conditions: deposition of cerium atoms in a background atmosphere of $\mathrm{O}_{2}$ or direct oxidation of a Ce-containing surface alloy. ${ }^{12,18,42-43}$ The source of oxygen in the process $\left(\mathrm{O}_{2}, \mathrm{H}_{2} \mathrm{O}\right.$ or $\left.\mathrm{N}_{2} \mathrm{O}\right)$ also affects the shape and distribution of ceria particles on the metal surface. In several cases the formation of well-ordered structures of ceria with (111), (110) and (100) fluorite terminations have been observed (see 
Figure 7 for an example). ${ }^{18,39-44,55}$ These oxide particles frequently exhibit rough areas and $\mathrm{O}$ vacancies. $^{18,55}$

The support can have a dramatic effect on the structure of the ceria islands in an inverse catalyst, as demonstrated in Figure 8 where STM/LEEM images and LEED patterns are displayed for low coverages of ceria on: $\operatorname{Au}(111),{ }^{55,56} \operatorname{Pt}(111),{ }^{50} \operatorname{Re}(0001),{ }^{54} \operatorname{Rh}(111),{ }^{43}$ $\mathrm{Ru}(0001),{ }^{45}$ and $\mathrm{Cu}(111) .{ }^{34}$ To generate these systems, Ce was usually dosed to the metal substrates under an atmosphere of oxygen. In all cases, the small lattice parameter of the support leads to significant lattice mismatch with the ceria $(\mathrm{a}=3.83 \AA)$ resulting in strain at the interface with the oxide, and influencing the island morphology. The variation in LEED patterns demonstrates the rich interactions between the ceria and the support, including the presence of rotated ceria domains as well as highlighting the presence of oxide overlayers on the substrates themselves, e.g. $\operatorname{Rh}(111)-(2 \times 2)-O{ }^{43}$

As described above for $\mathrm{FeO}_{\mathrm{x}} / \mathrm{Pt}(111)$ and $\mathrm{FeO}_{\mathrm{x}} / \mathrm{Au}(111)$, the chemical nature of the metal substrate can have a strong effect on the relative stability and average oxidation state of the oxide overlayer in $\mathrm{CeO}_{\mathrm{x}} / \mathrm{M}(111)$ systems. ${ }^{15,39,57,58}$ Theoretical calculations for the interaction of a $\mathrm{Ce}_{6} \mathrm{O}_{13}$ cluster or a single layer of $\mathrm{CeO}_{2}$ with $\mathrm{Cu}(111), \mathrm{Ag}(111)$ and $\mathrm{Au}(111)$ pointed to an increase in the bonding interactions following the sequence: gold $<$ silver $<$ copper. ${ }^{39}$ Upon deposition of $\mathrm{Ce}_{6} \mathrm{O}_{13}$ on $\mathrm{Ag}(111)$ or $\mathrm{Cu}(111)$, see Figure 9, all the cerium cations in the cluster were reduced to an oxidation state of $3+{ }^{39}$ An identical exercise on $\mathrm{Au}(111)$ produced four $\mathrm{Ce}^{3+}$ cations and two $\mathrm{Ce}^{4+}$ cations. The calculated percentage of $\mathrm{Ce}^{3+}$ cations in the single layer of $\mathrm{CeO}_{2}$ in contact with the metals was $50 \%$ on $\mathrm{Au}(111), 75 \%$ on $\mathrm{Ag}(111)$ and $86 \%$ on $\mathrm{Cu}(111){ }^{39}$ Thus, the bonding of ceria to a metal reduces the ceria, but the degree of reduction changes from one metal to another. The electronic perturbations seen for ceria in the inverse $\mathrm{CeO}_{\mathrm{x}} / \mathrm{M}(111)$ 
systems ${ }^{15,39,57,58}$ lead to interesting catalytic properties and these systems are highly active for the oxidation of $\mathrm{CO},{ }^{15,18,42}$ the water-gas shift, ${ }^{28,53,58}$ and the hydrogenation of $\mathrm{CO}_{2} \cdot{ }^{34,59}$

Figure 10 presents data for the oxidation of $\mathrm{CO}$ on $\mathrm{Pt}(111)$ and on a $\mathrm{CeO}_{\mathrm{x}} / \mathrm{Pt}(111)$ surface with 0.3 and $0.7 \mathrm{ML}$ of the oxide. ${ }^{15}$ For the $\{\mathrm{CO}+\mathrm{O}\} / \mathrm{Pt}(111)$ reaction system, on the macroscopic scale, two stable steady states have been found: ${ }^{15}$ a low-reactivity state with a surface mainly covered by $\mathrm{CO}$ and a high-reactivity state with a predominantly oxygen-covered surface. A change in the reaction conditions can cause kinetic transitions between these two states and a hysteric loop has been observed. ${ }^{15}$ In Figure 10c, the red curve shows kinetic data for $\mathrm{CO}$ oxidation on plain $\mathrm{Pt}(111)$. It starts with a low pressure of $\mathrm{CO}$ within the steady state of high reactivity which loses its stability upon approaching the transition point $\tau_{\mathrm{A}}$. For the reverse scan the steady state of low reactivity becomes unstable at $\tau_{\mathrm{B}}$. The STM images at the top of Figure 10 show the dispersion of ceria particles on the platinum substrate. On these surfaces the oxidation of $\mathrm{CO}$ occurs faster than on plain $\mathrm{Pt}(111)$, Figure $10 \mathrm{c}, \mathrm{d}$. This is mainly due to a ceriaenhancement in the sticking coefficient of $\mathrm{O}_{2} \cdot{ }^{15} \mathrm{~A}$ very similar trend have been found when comparing the rates of $\mathrm{CO}$ oxidation on $\mathrm{Cu}(111)$ and $\mathrm{CeO}_{\mathrm{x}} / \mathrm{Cu}(111) \cdot{ }^{52}$ The results of theoretical calculations indicate that the $\mathrm{Ce}^{3+}$ sites in the $\mathrm{Ce}_{6} \mathrm{O}_{13} / \mathrm{Cu}(111)$ system shown in Figure 9 adsorb $\mathrm{O}_{2}$, dissociate the molecule, and release atomic $\mathrm{O}$ for reaction with $\mathrm{CO}$ in an easy way. ${ }^{52}$ Indeed, combined studies of XPS and STM have established that small ceria particles deposited on copper are very efficient for adsorbing and dissociating the $\mathrm{O}_{2}$ molecule. ${ }^{52}$ The inverse $\mathrm{CeO}_{\mathrm{x}} / \mathrm{Cu}(111)$ catalysts have activities for the $2 \mathrm{CO}+\mathrm{O}_{2} \rightarrow 2 \mathrm{CO}_{2}$ reaction that are similar or larger than those reported for surfaces of expensive noble metals such as $\operatorname{Rh}(111), \operatorname{Pd}(110)$ and $\mathrm{Pt}(100) .{ }^{52}$ The key to this activity is the existence of $\mathrm{Ce}^{3+}$ sites in the oxide-metal interface which bind $\mathrm{O}$ atoms weaker than the $\mathrm{Ce}^{3+}$ sites of bulk ceria. ${ }^{39,52}$ 
Figure 11a shows data for the water-gas shift (WGS) reaction on $\mathrm{CeO}_{\mathrm{x}} / \mathrm{Au}(111)$ and $\mathrm{CeO}_{\mathrm{x}} / \mathrm{Cu}(111)$ catalyst. $^{14,53,60}$ The experiments were done on the inverse oxide/metal catalysts shown in Figures 7 and $11 \mathrm{~b}$. The initial composition of these catalysts were $\mathrm{CeO}_{2} / \mathrm{Au}(111)$ and $\mathrm{CeO}_{2} / \mathrm{CuO}_{\mathrm{x}} / \mathrm{Cu}(111)$, but they underwent substantial reduction under WGS reaction conditions and transformed into nanoparticles of $\mathrm{Ce}_{2} \mathrm{O}_{3}$ supported on $\mathrm{Au}(111)$ and $\mathrm{Cu}(111) .{ }^{14,53,60} \mathrm{Cu}(111)$ is a typical benchmark catalyst for the WGS. ${ }^{61,62} \mathrm{Au}(111)$ does not catalyze the reaction because it is not able to dissociate the water molecule. ${ }^{14}$ The deposition of nanoparticles of $\mathrm{Ce}_{2} \mathrm{O}_{3}$ on $\mathrm{Au}(111)$ produces a highly efficient catalyst for the WGS, Figure $11 \mathrm{a} .{ }^{14}$ In the $\mathrm{Ce}_{2} \mathrm{O}_{3} / \mathrm{Au}(111)$ system, the oxide and the metal work in a cooperative way: the oxide dissociates the water, the metal adsorbs $\mathrm{CO}$, and the $\mathrm{OH}+\mathrm{CO}$ reaction occurs at the oxide-metal interface. ${ }^{14}$ Inverse $\mathrm{CeO}_{\mathrm{x}} / \mathrm{Cu}(111)$ and $\mathrm{CeOx} / \mathrm{Cu}$ powder catalysts are extremely active for the WGS, Figure 11a and refs ${ }^{53,63}$. Figure $11 \mathrm{c}, \mathrm{d}$ displays the calculated energy profile for the water-gas shift on a $\mathrm{Ce}_{6} \mathrm{O}_{13} / \mathrm{Cu}(111)$ system. ${ }^{60}$ The reaction essentially takes place at the ceria-copper interface. The key steps are the dissociation of water, the formation of an HOCO intermediate, and its decomposition into $\mathrm{H}$ and $\mathrm{CO}_{2} \cdot{ }^{60}$ Since the atoms in the oxide and metal function in a cooperative way, all the reaction barriers are relatively small (0.1-0.45 eV). They can be easily overcome at the temperatures investigated in the experiments $(550-625 \mathrm{~K}){ }^{53,60}$ The reaction mechanism suggested by the theoretical calculations leads to a $\mathrm{CO}_{2}{ }^{\delta-}$ species. This species has been detected in experiments using Ambient-pressure XPS and infrared spectroscopy. ${ }^{60}$

The inverse powder catalyst shown in Figure 2 is highly active for the synthesis of methanol. ${ }^{21}$ Surfaces of $\mathrm{ZnO} / \mathrm{Cu}(111)$ and $\mathrm{CeOx} / \mathrm{Cu}(111)$ also display high catalytic activity for the $\mathrm{CO}_{2}+3 \mathrm{H}_{2} \rightarrow \mathrm{CH}_{3} \mathrm{OH}+\mathrm{H}_{2} \mathrm{O}$ conversion. ${ }^{33,34,59}$ Figure 12 displays the rate of $\mathrm{CH}_{3} \mathrm{OH}$ production from $\mathrm{CO}_{2}$ hydrogenation on $\mathrm{ZnO} / \mathrm{Cu}(111)$ and $\mathrm{CeO}_{\mathrm{x}} / \mathrm{Cu}(111)$ surfaces with different 
coverages of the oxides. ${ }^{34}$ A significant enhancement in catalytic activity was found after the generation of the inverse oxide/metal catalysts. For both systems, the catalytic activity increased after the oxide deposition, reached a maximum and then decreased. ${ }^{33,34}$ In the case of $\mathrm{CeO}_{\mathrm{x}} / \mathrm{Cu}(111)$, the highest catalytic activity was seen when the $\mathrm{Cu}(111)$ surface was $30-40 \%$ covered by ceria. The results in Figure 12 indicate that ceria is better as a promoter of catalytic activity than zinc oxide. No catalytic activity was detected after completely covering the copper substrate, indicating that the $\mathrm{CO}_{2} \rightarrow \mathrm{CH}_{3} \mathrm{OH}$ transformation occurred at the $\mathrm{Cu}-\mathrm{CeO}_{\mathrm{x}}$ and $\mathrm{Cu}-$ $\mathrm{ZnO}$ interfaces. In the Arrhenius plots in Figure 12B, the apparent activation energy for methanol synthesis decreases from a value of $25 \mathrm{kcal} / \mathrm{mol}$ on $\mathrm{Cu}(111)$ to $16 \mathrm{kcal} / \mathrm{mol}$ on $\mathrm{ZnO} / \mathrm{Cu}(111)$ and to $13 \mathrm{kcal} / \mathrm{mol}$ on $\mathrm{CeO}_{\mathrm{x}} / \mathrm{Cu}(111) .{ }^{34}$ For the range of temperature studied $(500-600 \mathrm{~K})$, the ceria/copper system was always the best catalyst. The $\mathrm{Ce}^{3+}$ sites generated at the ceria-copper interface, see above, are directly involved in the binding and conversion of $\mathrm{CO}_{2}{ }^{34,59}$ The reaction mechanism predicted by theoretical calculations starts with the reverse water-gas shift reaction to yield carbon monoxide, $\mathrm{CO}_{2}+\mathrm{H}_{2} \rightarrow \mathrm{CO}+\mathrm{H}_{2} \mathrm{O}$, and then there is a step-by-step hydrogenation of this molecule at the oxide-metal interface: $\mathrm{CO} \rightarrow \mathrm{CHO} \rightarrow \mathrm{CH}_{2} \mathrm{O} \rightarrow \mathrm{CH}_{3} \mathrm{O} \rightarrow \mathrm{CH}_{3} \mathrm{OH} .{ }^{59}$

A comparison of the rate of methanol production shown in Figure 12 for $\mathrm{ZnO} / \mathrm{Cu}(111)$ with that found for a traditional $\mathrm{Cu} / \mathrm{ZnO}(000 \overline{1})$ configuration $^{64}$ shows that the inverse oxide/metal system is by far a superior catalyst (Figure 13). Therefore, it is not surprising that this is the active configuration seen in an industrial $\mathrm{Cu} / \mathrm{ZnO} / \mathrm{Al}_{2} \mathrm{O}_{3}$ powder catalyst (Figure 2). ${ }^{21,22}$ Furthermore, for the $\mathrm{CeO}_{\mathrm{x}} / \mathrm{Cu}(111)$ and $\mathrm{Cu} / \mathrm{CeO}_{2}(111)$ systems, ${ }^{34,59}$ the oxide/metal arrangement is once more a much better catalyst (Figure 13). In an oxide/metal arrangement, the metal-oxide interactions are stronger than in a metal/oxide arrangement due to the very low reactivity of bulk oxides where even the simple wetting of many metals is a problem. ${ }^{65,66}$ As mentioned above, the 
strong bonding associated with oxide/metal configurations can induce perturbations or modifications in the electronic properties of the oxide which eventually lead to novel chemical properties. $^{28,38,39}$

Nanoparticles of titania grow on $\mathrm{Au}(111)$ adopting a rutile or anatase phase with various crystal facets. ${ }^{67,68,69}$ Scanning tunneling spectroscopy indicates that the crystals have a size dependent electronic structure. This property could be useful in catalysis and photocatalysis. Indeed, inverse $\mathrm{TiO}_{2} / \mathrm{Au}(111)$ catalysts are highly active for the oxidation of $\mathrm{CO}^{70}$ and the watergas shift reaction. ${ }^{14}$ A size or thickness depended electronic structure has also been observed for overlayers of $\mathrm{MgO}$ on metals. ${ }^{28}$ The strong oxide-metal interactions seen for the deposition of nanoparticles of $\mathrm{FeOx},{ }^{31,36,37,40} \mathrm{CeO}_{2},{ }^{39,49,50} \mathrm{TiO}_{2}{ }^{67,68}$ and $\mathrm{MgO}^{28}$ on metals are a common phenomenon in inverse oxide/metal systems and can have a strong impact in practical or technical applications.

In recent years, a substantial effort have been focused on the preparation of inverse oxide/metal catalysts which can be used in technical applications. ${ }^{6,7,19,70}$ Different methodologies have been followed for the synthesis of powder and film catalysts. ${ }^{5-8,10,19,21}$ An attractive approach for the preparation of $\mathrm{TiO}_{2} / \mathrm{Au}$ catalysts makes use of atomic layer deposition (ALD, Figure 1). ${ }^{7} \mathrm{~A}$ remarkable increase in the catalytic performance of $\mathrm{Au} / \mathrm{Al}_{2} \mathrm{O}_{3}$ and $\mathrm{Au} / \mathrm{SiO}_{2}$ for $\mathrm{CO}$ oxidation was found after depositing overlayers of $\mathrm{TiO}_{2}$ on the supported $\mathrm{Au}$ particles by ALD. ${ }^{7}$ The left side in Figure 14 displays HR-TEM images obtained after depositing $\mathrm{TiO}_{2}$ on unsupported Au particles with a size around $20 \mathrm{~nm}^{7}$ After 20 cycles of $\mathrm{TiO}_{2} \mathrm{ALD}$, islands of titania (highlighted by the black arrows) appeared on the corner and edge sites of the gold nanoparticles. In general, the $\mathrm{TiO}_{2}$ grew forming patches of islands instead of forming a uniform layer of the oxide on the gold substrate. A similar behavior has been observed in STM images for 
$\mathrm{TiO}_{2} / \mathrm{Au}(111) .{ }^{59,60,61}$ The right-side panel in Figure 14 compares the catalytic activity for CO oxidation of plain $\mathrm{Au} / \mathrm{Al}_{2} \mathrm{O}_{3}\left(0\right.$ cycles of $\left.\mathrm{TiO}_{2} \mathrm{ALD}\right)$ and $\mathrm{TiO}_{\mathrm{x}} / \mathrm{Au} / \mathrm{Al}_{2} \mathrm{O}_{3}$ systems with different coatings of titania. ${ }^{7}$ The formation of a titania-gold interface induces a drastic decrease $(>150$ degrees) in the temperature for light-off of the catalytic system. ${ }^{7}$ The $\mathrm{TiO}_{\mathrm{x}} / \mathrm{Au} / \mathrm{Al}_{2} \mathrm{O}_{3}$ catalyst with the highest activity ( 20 cycles of $\mathrm{TiO}_{2} \mathrm{ALD}$ ) is able to perform the oxidation of $\mathrm{CO}$ below 0 ${ }^{\circ} \mathrm{C}$. An increase in the amount of titania deposited (50 cycles of $\mathrm{TiO}_{2} \mathrm{ALD}$ ) leads to a drop in catalytic activity. It appears that small particles of $\mathrm{TiO}_{2}$ are required for the best catalytic performance. An identical trend has been observed in experiments for $\mathrm{CO}$ oxidation in $\mathrm{TiO}_{2} / \mathrm{Au}(111)^{70}$

$\mathrm{TiO}_{2} / \mathrm{Au}$ catalysts have also been prepared by immersing nanoporous (Np) gold into a precursor solution that contained titania. ${ }^{6}$ The top part of Figure 15 shows cross-sectional images of HR-TEM for $\mathrm{TiO}_{2} / \mathrm{Au}$ catalysts with a small (a) and a large (b) coverage of titania. ${ }^{6}$ In Figure 15a, there are isolated particles or island of titania on the nanoporous gold. On the other, in the system shown in Figure 15b there a coating of titania covering most of the gold substrate. ${ }^{6}$ Bare nanoporous gold displayed limited activity for the oxidation of $\mathrm{H}_{2}$ (Figure 15c). The deposition of titania on the gold substrate again improved the catalytic performance of the system. The best $\mathrm{TiO}_{2} / \mathrm{Np}$-Au catalyst in Figure $15 \mathrm{c}$ was $\sim 4$ times more active than bare Np-Au. Furthermore, the apparent activation energy decreased from $8.4 \mathrm{kcal} / \mathrm{mol}$ on $\mathrm{Np}-\mathrm{Au}$ to 4.5 $\mathrm{kcal} / \mathrm{mol}$ on $\mathrm{TiO}_{2} / \mathrm{Np}-\mathrm{Au}^{6}{ }^{6}$ As seen in other studies, ${ }^{7,70}$ the coverage of titania had a strong effect on the performance of the catalyst: A system with isolated $\mathrm{TiO}_{2}$ particles (Figure 15a) displayed a higher catalytic activity than a system with almost a full layer of titania (Figure $15 b$ ). ${ }^{6}$

Sequential impregnation can be used for the preparation of powders of inverse catalysts. ${ }^{19,20,63}$ This methodology has been used to deposit nanoparticles of ceria on $\mathrm{CuO} .{ }^{19}$ The 
$\mathrm{CeO}_{2} / \mathrm{CuO}$ system was highly active for preferential oxidation of $\mathrm{CO}$ in a hydrogen-rich stream (CO-prox $)^{19}$ and upon exposure to $\mathrm{CO}$ or $\mathrm{H}_{2}$ transformed into an inverse $\mathrm{CeO}_{\mathrm{x}} / \mathrm{Cu}$ system which was an excellent catalyst for the water-gas shift reaction. ${ }^{63}$ The reduction in hydrogen of metal/oxide catalysts can lead to migration of the oxide yielding an inverse oxide/metal configuration. ${ }^{9-11,21-26,63}$ In principle, one could modify the properties of the oxide phase to facilitate the migration of clusters of the oxide towards the metal. For example, in the case of $\mathrm{Cu} / \mathrm{ZnO}$ catalysts for methanol synthesis, the doping of the $\mathrm{ZnO}$ support with $\mathrm{Al}^{3+}$ and $\mathrm{Ga}^{3+}$ cations facilitates the formation of an inverse $\mathrm{ZnO} / \mathrm{Cu}$ catalyst (Figure 16) and eventually enhances the catalytic activity. ${ }^{22}$ In inverse oxide/metal systems, there may be situations in which there is not a sharp oxide-metal interface and atoms of the metal substrate migrate into the lattice of the oxide overlayer. ${ }^{71}$ This migration, or doping, can also be used to enhance the reactivity of the oxide overlayer. ${ }^{71}$ This effect is particular useful when working with nonreducible oxides which by themselves have a tendency to a low chemical activity. ${ }^{71}$

Summary and Outlook. Inverse oxide/metal catalysts have shown to be excellent systems for studying the role of the oxide and the oxide-metal interface in a catalytic reaction. In recent studies, using model systems and powders, it has become clear that these systems can have special catalytic properties due to strong oxide-metal interactions difficult to obtain when depositing a metal on a regular oxide support. As a consequence of these strong interactions, oxide phases that are not seen or are metastable in a bulk oxide become stable in an oxide/metal system opening the possibility of new chemical properties. Strong oxide-metal interactions which lead to significant electronic perturbations in the oxide have been observed in systems that involve reducible $\left(\mathrm{FeO}_{\mathrm{x}}, \mathrm{CeO}_{\mathrm{x}}, \mathrm{TiO}_{\mathrm{x}}\right)^{14,18,35,37,38,54}$ and non-reducible oxides $\left(\mathrm{MgO}, \mathrm{Al}_{2} \mathrm{O}_{3}\right) .{ }^{28,38}$ 
There are several basic issues associated with the behavior of oxide-metal interfaces which need more study. To examine the morphology of an oxide-metal interface in model or powder systems is not an easy task and more detailed work with electron microscopies and scanning probes is necessary. ${ }^{21,72}$ What parameters control the growth mode of an oxide over a metal substrate? In this area there have been some advances for work with model systems ${ }^{10,13,18,30-32,36,37,42-50}$ but very little is known when dealing with powders or rough films. ${ }^{5-}$ 7,21,72 Additional work must be done to determine the relative importance of differences in surface free energies or the mismatch between the lattice parameters of the oxide and metal. In oxide/metal systems involving $\mathrm{FeOx}, \mathrm{CeOx}$, TiOx and $\mathrm{ZnO}$, oxide phases or crystal structures which are not stable or metastable in bulk materials have been found. ${ }^{22.31,33,36,37,45,47,55,67}$ It is not clear what triggers the stabilization of these phases or crystal structures or how to control such a phenomenon for use in practical applications. Future studies need to examine the role played by a mismatch between the lattice parameters of the oxide and metal substrate, and the effects of changes in electronic state induced by bonding with the metal.

Oxides are a diverse class of materials whose electronic properties cover the entire range from insulators to semiconductors and conductors. In principle, several electronic phenomena can occur when an oxide-metal interface is formed. ${ }^{73}$ The terms SMSI and SOMI refer to manifestations of these phenomena that affect the metal or oxide component in the interface. Both types of interaction are important when defining the electronic and chemical properties of an inverse oxide/metal catalyst. Since SOMIs are common in these materials, a general theory or conceptual frame must be developed to explain and predict their electronic properties. How do the electronic properties depend on the nature of the metal and the oxide? For a given metal, what can we expect for bonding with an insulator or a semiconductor? And for a particular 
oxide, what will happen when going from a noble to a late or early transition metal? So far, these issues have been addressed only for a few oxide/metal combinations ${ }^{28,31,38,39}$ and a more systematic work is needed to help with the choice of metal and oxide for optimal catalyst performance. Such a knowledge is a pre-requisite for a rational design of inverse oxide/metal catalysts.

In the last fifteen years, many combinations of well-defined oxide/metal systems have been prepared, ${ }^{10-18,30-35,42-56}$ more or less empirically, involving different kinds of metals and oxides, but only a small fraction of them have been tested as catalysts and just for a limited number of reactions (CO oxidation, the water-gas shift, $\mathrm{CO} / \mathrm{CO}_{2}$ hydrogenation). ${ }^{10-18,25,30-25,51-}$ ${ }^{53,59}$ More broad studies are necessary in this area because the benefits in technical applications can be substantial. Catalysts containing metals and oxides are widely used in the control of environmental pollution, the conversion or reforming of hydrocarbons, and the synthesis of fine chemicals. ${ }^{74}$ Using inverse oxide/metal catalysts one should be able to explore in detail possible correlations between the structural, electronic and catalytic properties of oxide-metal interfaces. In-situ techniques (XPS, XAS, XRD, STM) could be combined to obtain fundamental information under reaction conditions. In addition, computational modeling could give a complementary view of the oxide-metal interface and offer inaccessible information on the atomic scale. An improved understanding of the factors controlling catalytic performance will permit a more rational approach to the design of catalysts.

Most of the work done so far for inverse oxide/metal catalysts has dealt with model systems in which the substrate is a single crystal. Recently, there has been a significant advance in the preparation of technical oxide/metal catalysts but more needs to be done in this area. Ideally, one must be able to control in a precise way the size of the oxide particles deposited and 
how they wet the metal substrate. The development of synthetic methods which can be applied to the synthesis of a broad range of powders with an oxide/metal configuration is a challenging task.

Finally, inverse catalysts also could be generated by depositing nanoparticles of a sulfide, carbide or nitride on a metal surface. Figure 17 shows STM images for $\mathrm{RuS}_{2}$ and $\mathrm{MoS}_{2}$ on a $\mathrm{Au}(111)$ substrate..$^{75,76}$ The ionic character of these compounds is smaller than in an oxide and they do have catalytic properties on their own. ${ }^{76,77,78,79,80}$ An inverse $\mathrm{MoS}_{2} / \mathrm{Au}(111)$ catalyst has been studied in detail showing edge atoms in the $\mathrm{MoS}_{2}$ nanoparticles (Figure 17a,b) which have special electronic and catalytic properties relevant for hydrodesulfurization processes. ${ }^{76,81}$ Thus, an exciting area of work for the future should involve the study of the catalytic properties of inverse sulfide/metal, carbide/metal and nitride/metal systems. The information acquired from these studies might constitute an important part for an integral library on the performance of inverse catalysts.

\section{AUTHOR INFORMATION}

\section{Corresponding author:}

José A Rodriguez, e-mail: rodrigez@bnl.gov

\section{Notes:}

The authors declare no competing financial interests

\section{Biographies}

Jose A. Rodriguez did part of his education at Simon Bolivar University in Venezuela, where he received BS degrees in Chemistry and Chemical Engineering, and a MS in Theoretical Chemistry. He moved to the United States to get a PhD in Physical Chemistry at Indiana University, Bloomington. He is currently 
a Senior Scientist at Brookhaven National Laboratory and an Adjunct Professor in the Department of Chemistry of SUNY Stony Brook. Nowadays, Dr Rodriguez is involved in the preparation and study of nanocatalysts utilized for the production of clean fuels and the control of environmental pollution.

Ping Liu graduated from Jilin University in China with a Ph.D. in Condensed Matter Physics. Then she spent two years at the Technical University of Denmark as an postdoctoral fellow. After that, she has been working at BNL. She is now a scientist in Chemistry Department at Brookhaven National Laboratory (BNL) and an Adjunct Associate Professor in the Department of Chemistry of SUNY Stony Brook. Her research has focused on theoretical description of nanostructures, surfaces and their catalytic applications in cleaning of conventional oil-derived fuels, production, conversion and utilization of nonconventional fuels such as hydrogen and ethanol.

Jesus Graciani is an Assistant Professor in the Physical Chemistry Department at University of Seville (Spain). He obtained his BS degree in Chemistry (2002) and PhD in Theoretical Chemistry (2007) at University of Seville (Spain). He was a Research Assistant in the Department of Chemistry at Brookhaven National Laboratory in New York (2008-9). His research is focused on theoretical simulation of Surface Chemistry processes, especially on elucidating reaction mechanisms of heterogeneous catalysts involving both oxides and metals

Sanjaya D. Senanayake received his B.Tech. (Materials) with Hons in 2001 and PhD in Chemistry in 2006 from The University of Auckland in New Zealand. After postdoctoral work with Oak Ridge National Lab and Brookhaven National Laboratory he is at present an Associate Scientist in the Department of Chemistry at Brookhaven National Laboratory. He also served as the beamline scientist at $\mathrm{X} 7 \mathrm{~B}$ at the National Synchrotron Light Source.

David C. Grinter received a MSci. in Natural Sciences in 2007 from Cambridge University, and a PhD in Chemistry in 2011 from University College London. Following post-doctoral research at University College London, he joined the Catalysis: Reactivity and Structure group in the Chemistry department at Brookhaven National Laboratory in 2015, where he is currently a research associate.

Dario Stacchiola is a Chemist at Brookhaven National Laboratory and Adjunct Professor at Michigan Technological University. He obtained his BS degree (1997) at UNSL (Argentina), PhD (2002) at the University of Wisconsin-Milwaukee, and was a Humboldt Research Fellow at the Fritz-Haber-Institute in Berlin (2005-7). His research interest is in Surface Chemistry, in particular on the structure-reactivity relationships in Catalysis

Jan Hrbek was a senior scientist at BNL until his retirement in March 2013. He obtained his undergraduate and graduate degrees in physical chemistry at Charles University and the Czechoslovak Academy of Sciences in Prague. His long-lasting research interest in surface science and catalysis continues. He has investigated correlations between the physical and chemical properties of inverse oxide/metal catalysts for almost twenty years.

Javier Fernandez-Sanz is a Professor at the Department of Physical Chemistry in the University of Sevilla (Spain). He got his PhD at the University of Zaragoza and has been a Visiting Professor at Stanford University. His research activities fall within the computational materials science general topic, and can be broadly described as the development and application of methods and models to simulate 
material properties and surface reactions using quantum mechanical theory and statistics. He has a strong interest in the study of the structural and electronic properties of metal-oxides, metal/metal-oxide interfaces, and mixed metal-oxides nanostructures.

\section{ACKNOWLEDGEMENTS}

Many of the studies described above were done in collaboration with members of the Catalysis Group at Brookhaven National Laboratory and collaborators from the Universidad Central de Venezuela and the Institute of Catalysis-Madrid: A. Baber, S. Agnoli, L. Barrio, M. Estrella, J. Evans, M. Fernandez-Garcia, J. Hanson, A. Hornes, S. Kundu, S. Ma, A. MartinezArias, K. Mudiyanselage, J.-B. Park, P.J. Ramirez, A. Vidal, F. Yang and X. Zhao. Many thanks to all of them. The work carried out at Brookhaven National Laboratory was supported by the US Department of Energy (Chemical Sciences Division, DE-SC0012704). Part of these studies was done at the National Synchrotron Light Source and at the Center for Functional Nanomaterials of BNL, which are supported by the U.S. Department of Energy.

\section{REFERENCES}

${ }^{1}$ Thomas, J.M.; Thomas, W.J. Principles and Practice of Heterogeneous Catalysis, $2^{\text {nd }}$ Ed; Wiley-VCH: New York, 2015.

${ }^{2}$ Metal Oxide Catalysis; Jackson S.D.,Hargreaves J.S.J., Eds.; Wiley: New York, 2008.

3 Ross, J.R.H. Heterogeneous Catalysis: Fundamentals and Applications; Elsevier: New York, 2011.

${ }^{4}$ Nanotechnology in Catalysis, Zhou, B., Hermans, S., Somorjai G.A., Eds; Kluwer-Plenum: New York, 2004.

${ }^{5}$ Meng, B.; Zhao, Z.; Chen, Y.; Wang, X.; Li, Y.; Qiu, J. Low-Temperature Synthesis of Mnbased Mixed Metal Oxides with Novel Fluffy Structures as Efficient Catalysts for Selective Reduction of Nitrogen Oxides by Ammonia. Chem. Commun. 2014, 50, 12396-12399.

${ }^{6}$ Qadir, K.; Quynh, B.T.P.; Lee, H.; Moon, S.Y.; Kim, S.H.; Park, J.Y. Tailoring Metal-Oxide Interfaces of Inverse Catalysts of $\mathrm{TiO}_{2} /$ Nanoporous-Au under Hydrogen Oxidation. Chem. Commun. 2015, 51, 9620-9623. 
7 Wang, C.; Wang, H.; Yao, Q.; Yan, H.; Li, J.; Lu, J. Precisely Applying $\mathrm{TiO}_{2}$ Overcoat on Supported Au Catalysts Using Atomic Layer Deposition for Understanding the Reaction Mechanism and Improved Activity in CO Oxidation. J. Phys. Chem. C, 2016, 120, 478-486.

8 Fernández-García, M.; Martínez-Arias, A.; Hanson, J.C.; Rodriguez, J.A. Nanostructured Oxides in Chemistry: Characterization and Properties. Chem. Rev. 2004, 104, 4063-4104.

9 Schwab, G.-M. Electronics of Supported Catalysts. Adv. Catal. 1978, 27, 1-22.

${ }^{10}$ Hayek, K.; Fuchs, M.; Klötzar, B.; Reichl, W.; Rupprechter, G. Studies of Metal-Support Interactions with "Real" and "Inverted" Model Systems: Reactions of CO and Small Hydrocarbons with Hydrogen on Noble Metals in Contact with Oxides. Topics Catal. 2000, 13, 53-66.

11 Demmin, R.A.; Ko, C.S.; Gorte, R.J. Effect of Titania on the Chemisorption and Reaction Properties of Pt. J. Phys. Chem. 1985, 89, 1151-1134.

12 Jennison, D.R.; Dulub, O.; Hebenstreit, W.; Diebold, U. Structure of Ultrathin TiO $\mathrm{x}_{\mathrm{x}}$ Film, Formed by the Strong Metal Support Interaction (SMSI), on Pt Nanocrystals on $\mathrm{TiO}_{2}(110)$. Surf. Sci. 2001, 492 L677-L687.

13 Martynova, Y.; Liu, B.-H.; McBriarty, M.E.; Groot, I.M.N.; Bedzyk, M.J.; Shaikhutdinov, S.; Freund, H.-J. CO oxidation over ZnO Films at Near-Atmospheric Pressures. J. Catal. 2013, 301, 227-232.

14 Rodriguez, J.A.; Ma, S.; Liu, P.; Hrbek, J.; Evans, J.; Perez, M. Activity of $\mathrm{CeO}_{\mathrm{x}}$ and $\mathrm{TiO}_{\mathrm{x}}$ Nanoparticles Grown on $\mathrm{Au}(111)$ in the Water-gas Shift Reaction. Science, 2007, 318, 17571570 .

15 Suchorski, Y.; Wrobel, R.; Becker, S.; Weiss, H. CO Oxidation on a $\mathrm{CeO}_{\mathrm{x}} / \mathrm{Pt}(111)$ Inverse Model Catalyst Surface: Catalytic Promotion and Tuning of Kinetic Phase Diagrams. J. Phys. Chem. C, 2008, 112, 20012-20017.

16 Yan, T.; Redman, D.W.; Yu, W.-Y.; Flaherty, D.W.; Rodriguez, J.A.; Mullins, C.B. CO Oxidation on Inverse on $\mathrm{Fe}_{2} \mathrm{O}_{3} / \mathrm{Au}(110)$ Model Catalysts. J. Catal. 2012, 294, 216-222.

17 Nakamura, I.; Mantoku, H.; Furukawa, T.; Fujitani, T. Active Sites for the Hydrogen Dissociation over $\mathrm{TiO}_{\mathrm{x}} / \mathrm{Au}(111)$ Surfaces. J. Phys. Chem. C, 2011, 115, 16704-16080.

18 Eck, S.; Castellarin-Cudia, C.; Surnev, S.; Prince, K.; Ramsey, M.; Netzer, F.: Adsorption and reaction of $\mathrm{CO}$ on a ceria-Rh(111) "inverse model catalyst" surface. Surface Science 2003, 536, 166-176.

19 Hornes, A.; Hungria, A.; Bera, P.; Camara, A.; Fernandez-Garcia, M.; Martinez-Arias, A.; Barrio, L.; Estrella, M.; Zhou, G.; Fonseca, J.; Hanson, J.; Rodriguez, J.: Inverse $\mathrm{CeO}_{2} / \mathrm{CuO}$ catalyst as an alternative to classical direct configurations for preferential oxidation of $\mathrm{CO}$ in hydrogen-rich stream. J. Amer. Chem. Soc. 2010, 132, 34-35. 
20 Yeung, C.M.Y.; Tsang, S.C. Noble Metal Core-Ceria Shell Catalysts for the Water-Gas Shift Reaction. J. Phys. Chem. C, 2009, 113, 6074-6087.

${ }^{21}$ Lunkenbein, T.; Schumann, J.; Behrens, M.; Schlögl, R.; Willinger, M.G. Formation of a ZnO Overlayer in Industrial $\mathrm{Cu} / \mathrm{ZnO} / \mathrm{Al}_{2} \mathrm{O}_{3}$ Catalysts Induced by Strong Metal-Support Interactions. Angew. Chem. Int. Ed. 2015, 54, 4544-4548.

${ }^{22}$ Schumann, J.; Eichelbaum, M.; Lunkenbein, T.; Thomas, N.; Álvárez-Galvan, M.C.; Schlögl, R.; Behrens, M. Promoting Strong Metal Support Interaction: Doping ZnO for Enhanced Activity of Cu/ZnO:M (M= Al, Ga, Mg) Catalysts. ACS Catal. 2015, 5, 3260-3270.

23 Wen. W.; Jing, L.; White, M.G.; Marinkovic, N.; Hanson, J.C.; Rodriguez, J.A. In-situ Timeresolved Characterization of Novel $\mathrm{Cu}-\mathrm{MoO}_{2}$ Catalysts during the Water-gas Shift Reaction. Catal. Lett. 2007, 113, 1-6.

24 Braunschweig, E.J.; Logan, A.D.; Datye, A.K.; Smith, D.J. Reversibility of Strong MetalSupport Interactions on $\mathrm{Rh} / \mathrm{TiO}_{2}$. J. Catal. 1989, 118, 227-237.

25 Vayssilov, G.N.; Lykhach, Y.; Migani, A.; Staudt, T.; Petrova, G.P.; Tsud, N.; Skála, T.; Bruix, A.; Illas, F.; Prince, K.C.; Matolín, V.; Neyman, K.M.; Libuda, J. Support Nanostructure Boosts Oxygen Transfer to Catalytically Active Platinum Nanoparticles. Nature Materials, 2011, 10, 310-315.

26 Matte, L.P.; Kilian, A.S.; Luza, L.; Alves, M.C.M.; Morais, J.; Baptista, D.L.; Dupont,J,; Bernardi, F. Influence of the $\mathrm{CeO}_{2}$ Support on the Reduction Properties of $\mathrm{Cu} / \mathrm{CeO}$ and $\mathrm{Ni} / \mathrm{CeO}_{2}$ Nanoparticles. J. Phys. Chem. C, 2015, 119, 26459-26470.

27 Tauster, S.J. Accounts of Chem. Research, 1987, 20, 389-394.

28 Pacchioni, G.; Freund, H.J. Electron Transfer at Oxide Surfaces. The MgO Paradigm: from Defects to Ultrathin Films. Chem. Rev. 2013, 113, 4035-4072.

29 Sano, M.; Adaniya, T.; Fujitani, T.; Nakamura, J. Oxidation of a Zn-deposited Cu(111) Surface Studied by XPS and STM. Surf. Sci. 2002, 514, 261-268.

30 Rodriguez, J.A.; Hrbek, J. Inverse Oxide/Metal Catalysts: A Versatile Approach for Activity Tests and Mechanistic Studies. Surf. Sci. 2010, 604, 241-244.

31 Ning, Y.; Wei, M.; Yu, L. Yang, F.; Chang, R.; Liu, Z.; Fu, Q.; Bao, X. Nature of Interface Confinement Effect in Oxide/Metal Catalysts. J. Phys. Chem. C, 2015, 119, 27556-27561.

32 Yu, L.; Liu, Y.; Yang, F.; Evans, J.; Rodriguez, J.A.; Liu, P. CO Oxidation on GoldSupported Iron Oxides: New Insights into Strong Oxide-Metal Interactions. J. Phys. Chem. C, 2015, 119, 16614-16622. 
33 Nakamura, J.; Nakamura, I.; Uchijima, T.; Kanai, Y.; Watanabe, T.; Saito, M.; Fujitani, T. A Surface Science Investigation of Methanol Synthesis over a Zn-Deposited Polycrystalline $\mathrm{Cu}$ Surface. J. Catal. 1996, 160, 65-75.

34 Senanayake, S.D.; Ramirez, P.J.; Waluyo, I.; Kundu, S.; Mudiyanselage, K.; Liu, Z.; Liu, Z.; Axnanda, S.; Stacchiola, D.J.; Evans, J.; Rodriguez, J.A. Hydrogenation of $\mathrm{CO}_{2}$ to Methanol on $\mathrm{CeO}_{\mathrm{x}} / \mathrm{Cu}(111)$ and $\mathrm{ZnO} / \mathrm{Cu}(111)$ Catalysts: Role of the Metal-Oxide Interface and Importance of $\mathrm{Ce}^{3+}$ Sites. J. Phys. Chem. C, 2016, 120, 1778-1784.

35 Höcker, J.; Cartas, W.; Schaefer, A.; Baumer, M.; Weaver, J.F.; Falta, J.; Flege, J.I. Growth, Structure, and Stability of the High-Index $\operatorname{TbOx}(112)$ Surface on $\mathrm{Cu}(111)$. J. Phys. Chem. C, 2015, 119, 14175-14184.

36 Deng, X.; Matranga, C., Selective Growth of $\mathrm{Fe}_{2} \mathrm{O}_{3}$ nanoparticles and islands on $\mathrm{Au}(111) . J$. Phys. Chem. C 2009, 113, 11104-11109.

37 Khan, N. A.; Matranga, C., Nucleation and growth of Fe and FeO nanoparticles and films on $\mathrm{Au}(111)$. Sur. Sci. 2008, 602, (4), 932-942.

${ }^{38}$ Vidal, A.; Liu, P. Density Functional Study of Water-Gas Shift Reaction on $\mathrm{M}_{3} \mathrm{O}_{3 \mathrm{x}} / \mathrm{Cu}(111)$. Phys. Chem. Chem. Phys. 2012, 14, 16626-16632.

39 Graciani, J.; Vidal, A.B.; Rodriguez, J.A.; Sanz, J.F. Unraveling the Nature of the OxideMetal Interaction in Ceria-Based Noble Metal Inverse Catalysts. J. Phys. Chem. C, 2014, 118, 26931-26938.

40 Sun, Y.; Qin, Z.; Lewandowski, M.; Carrasco, E.; Sterrer, M.; Shaikhutdinov, S.; Freund, H.: Monolayer iron oxide film on platinum promotes low temperature $\mathrm{CO}$ oxidation. Journal of Catalysis 2009, 266, 359-368.

${ }^{41}$ Trovarelli, A. Catalytic properties of ceria and $\mathrm{CeO}_{2}$-containing materials. Catalysis ReviewsScience and Engineering 1996, 38, 439-520

42 Castellarin-Cudia, C.; Surnev, S.; Schneider, G.; Podlucky, R.; Ramsey, M.; Netzer, F.: Strain-induced formation of arrays of catalytically active sites at the metal-oxide interface. Surface Science 2004, 554, L120-L126.

${ }^{43}$ Grinter, D. C.; Muryn, C.; Santos, B.; Shaw, B.-J.; Menteş, T. O.; Locatelli, A.; Thornton, G. Spectromicroscopy of a Model Water-Gas Shift Catalyst: Gold Nanoparticles Supported on Ceria. Journal of Physical Chemistry C. 2014, 118, 19194-19204.

44 Lu, J.; Gao, H.; Shaikhutdinov, S.; Freund, H.: Morphology and defect structure of the $\mathrm{CeO}_{2}(111)$ films grown on $\mathrm{Ru}(0001)$ as studied by scanning tunneling microscopy. Surface Science 2006, 600, 5004-5010. 
${ }^{45}$ Kaemena, B.; Senanayake, S. D.; Meyer, A.; Sadowski, J. T.; Falta, J.; Flege, J. I. Growth and Morphology of Ceria on Ruthenium (0001). Journal of Physical Chemistry C. 2013, 217, 221232.

46 Mullins, D.; Radulovic, P.; Overbury, S.: Ordered cerium oxide thin films grown on Ru(0001) and Ni(111). Surface Science 1999, 429, 186-198.

${ }^{47}$ Alexandrou, M.; Nix, R.M. The growth, structure and stability of ceria overlayers on $\operatorname{Pd}(111)$. Surf. Sci. 1994, 321, 47-57.

${ }^{48}$ Berner, U.; Schierbaum, K.: Cerium oxides and cerium-platinum surface alloys on Pt(111) single-crystal surfaces studied by scanning tunneling microscopy. Physical Review B 2002, 65, 235404.

49 Berner, U.; Schierbaum, K.; Jones, G.; Wincott, P.; Haq, S.; Thornton, G.: Ultrathin ordered $\mathrm{CeO}_{2}$ overlayers on $\mathrm{Pt}(111)$ : interaction with $\mathrm{NO}_{2}, \mathrm{NO}, \mathrm{H}_{2} \mathrm{O}$ and $\mathrm{CO}$. Surface Science 2000, 467, 201-213.

${ }^{50}$ Grinter, D. C.; Ithnin, R.; Pang, C. L.; Thornton, G. Defect Structure of Ultrathin Ceria Films on Pt(111): Atomic Views From Scanning Tunnelling Microscopy. Journal of Physical Chemistry C. 2010, 114, 17036-17041.

51 Matolin, V.; Sedlacek, L.; Matolinova, I.; Sutara, F.; Skala, T.; Smid, B.; Libra, J.; Nehasil, V.; Prince, K.: Photoemission spectroscopy study of $\mathrm{Cu} / \mathrm{CeO}_{2}$ systems: $\mathrm{Cu} / \mathrm{CeO}{ }_{2}$ nanosized catalyst and $\mathrm{CeO}_{2}(111) / \mathrm{Cu}(111)$ inverse model catalyst. Journal of Physical Chemistry C 2008, $112,3751-3758$.

52 Yang, F.; Graciani, J.; Evans, J.; Liu, P.; Hrbek, J.; Frd-Sanz, J.; Rodriguez, J.: CO oxidation on inverse $\mathrm{CeO}_{\mathrm{x}} / \mathrm{Cu}(111)$ catalysts: High catalytic activity and ceria-promoted dissociation of $\mathrm{O}_{2}$. Journal of the American Chemical Society 2011, 133, 3444-3451.

53 Senanayake, S.; Sadowski, J.; Evans, J.; Kundu, S.; Agnoli, S.; Yang, F.; Stacchiola, D.; Flege, J.; Hrbek, J.; Rodriguez, J.: Nanopattering in $\mathrm{CeO}_{\mathrm{x}} / \mathrm{Cu}(111)$ : A new type of surface reconstruction and enhancement of catalytic activity. Journal of Physical Chemistry Letters 2012, 3, 839-843.

${ }^{54}$ Grinter, D. C.; Yim, C. M.; Pang, C. L.; Santos, B.; Mentes, T. O.; Locatelli, A.; Thornton, G. Oxidation State Imaging of Ceria Island Growth on $\operatorname{Re}(0001)$. Journal of Physical Chemistry C. 2013, 117, 16509-16514.

55 Zhao, X.; Ma, S.; Hrbek, J.; Rodriguez, J.A. Reaction of Water with Ce-Au(111) and $\mathrm{CeOx} / \mathrm{Au}(111)$ Surfaces: Photoemission and STM Studies. Surf. Sci. 2007, 601, 2445-2452. 
${ }^{56}$ Ma, T.; Surnev, S.; Netzer, F.P. Growth of Ceria Nano-Islands on a Stepped Au(788) Surface Materials 2015, 8, 5205-5215.

57 Bromley, S.; Moreira, I.; Neyman, K.; Illas, F.: Approaching nanoscale oxides: models and theoretical methods. Chemical Society Reviews 2009, 38, 2657-2670.

58 Rodriguez, J.; Graciani, J.; Evans, J.; Park, J.; Yang, F.; Stacchiola, D.; Senanayake, S.; Ma, S.; Perez, M.; Liu, P.; Sanz, J.; Hrbek, J.: Water-Gas shift reaction on a highly active inverse $\mathrm{CeO}_{\mathrm{x}} / \mathrm{Cu}(111)$ catalyst: Unique role of ceria nanoparticles. Angewandte Chemie-International Edition 2009, 48, 8047-8050.

59 Graciani, J.; Mudiyanselage, K.; Xu, F.; Baber, A. E.; Evans, J.; Senanayake, S. D.; Stacchiola, D. J.; Liu, P.; Hrbek, J.; Sanz, J. F.; Rodriguez, J. A. Highly Active Copper-CeriaTitania Catalysts for Methanol Synthesis from $\mathrm{CO}_{2}$. Science 2014, 345, 546-551.

60 Mudiyanselage, K.; Senanayake, S.D.; Feria, L.; Kundu, S.; Baber, A.E.; Graciani, J.; Vidal, A.B.; Agnoli, S.; Evans, J.; Chang, R.; et al.; Importance of the Metal-Oxide Interface in Catalysis: In Situ Studies of the Water-Gas Shift Reaction by Ambient-Pressure X-ray Photoelectron Spectroscopy. Angew. Chem. Int. Ed., 2013, 52, 5101-5105.

61 Nakamura, J.; Campbell, J.; Campbell, C.: Kinetics and mechanism of the water-gas shift reaction catalyzed by the clean and Cs-promoted $\mathrm{Cu}(110)$ surface - a comparison with $\mathrm{Cu}(111)$. Journal of the Chemical Society-Faraday Transactions 1990, 86, 2725-2734. Campbell, C.; Daube, K.: A surface science investigation of the water-gas shift reaction on $\mathrm{Cu}(111)$. Journal of Catalysis 1987, 104, 109-119.

62 Gokhale, A.; Dumesic, J.; Mavrikakis, M.: On the mechanism of low-temperature water gas shift reaction on copper. Journal of the American Chemical Society 2008, 130, 1402-1414.

63 Barrio, L.; Estrella, M.; Zhou, G.; Wen, W.; Hanson, J.; Hungria, A.; Hornes, A.; FernandezGarcia, M.; Martinez-Arias, A.; Rodriguez, J.: Unraveling the active site in copper-ceria systems for the Water-Gas shift reaction: In situ characterization of an inverse powder $\mathrm{CeO}_{2-\mathrm{x}} / \mathrm{CuO}-\mathrm{Cu}$ Catalyst. Journal of Physical Chemistry C 2010, 114, 3580-3587.

64 Yang, Y.; Evans, J.; Rodriguez, J.A.; White, M.G.; Liu, P. Fundamental studies of methanol synthesis from $\mathrm{CO}_{2}$ hydrogenation on $\mathrm{Cu}(111), \mathrm{Cu}$ clusters, and $\mathrm{Cu} / \mathrm{ZnO}(0001)$. Phys. Chem. Chem. Phys. 2010, 12, 9909-9917.

${ }^{65}$ Campbell, C.T. Ultrathin Metal Films and Particles on Oxide Surfaces: Structural, Electronic and Chemisorptive Properties. Surf. Sci. Reports, 1997, 27, 1-111.

${ }^{66}$ Henry, C. Surface Studies of Supported Model Catalysts. Surf. Sci. Reports, 1998, 31, 231325.

67 Song, Z.; Hrbek, J.; Osgood, R. Formation of $\mathrm{TiO}_{2}$ Nanoparticles by Reactive-Layer-Assisted Deposition and Characterization by XPS and STM. Nano Lett. 2005, 5, 1327-1332. 
68 Wu, C.; Marshall, M.S.; Castell, M.R. Surface Structures of Ultrathin T iO ${ }_{x}$ Films on Au(111). J. Phys. Chem. C, 2011, 115, 8643-8652.

69 Potapenko, D.V.; Osgood, R.M. Preparation of $\mathrm{TiO}_{2}$ Nanocrystallites by Oxidation of TiAu(111) Surface Alloy. Nano Lett. 2009, 9, 2378-2383.

70 Fujitani, T,; Nakamura, I. Mechanism and Active Sites of the Oxidation of CO over $\mathrm{Au} / \mathrm{TiO}_{2}$. Angew. Chem. Int. Ed. 2011, 50, 10144-10147.

${ }^{71}$ Nilius, N.; Freund, H.-J. Activating Nonreducible Oxides via Doping, Accounts of Chemical Research, 2015, 48, 1532-1539.

72 Willinger, M.G.; Zhang, W.; Bondarchuk, O.; Shaikhutdinov, S.; Freund, H.-J.; Schlögl, R. A Case of Strong Metal-Support Interactions: Combining Advanced Microscopy and Model Systems to Elucidate the Atomic Structure of Interfaces. Angew. Chem. Int. Ed. 2014, 53, 59986001.

${ }^{73}$ Noguera, C.; Finocchi, F.; Goniakowski, J. First principles studies of complex oxide surfaces and interfaces J. Phys. Condensed Matter 2004, 16, S2509-S2537.

74 Metal Oxide Catalysis, S.D. Jackson and J.S.J. Hargreaves (Eds), Wiley-VCH: New York, 2008.

75 Cai, T.; Song, Z.; Rodriguez, J.A.; Hrbek, J. Preparation and Structural Characterization of $\mathrm{RuS}_{2}$ Nanoislands on Au(111). J. Am. Chem. Soc. 2004, 126, 8886-8887.

76 Bruix, A.; Fuchtbauer, H.G.; Tuxen, A.K.; Walton, A.S.; Andersen, M.; Porsgaard, S.; Besenbacher, F.; Hammer, B.; Lauritsen, J.V. In Situ Detection of Active Edge Sites in SingleLayer $\mathrm{MoS}_{2}$ Catalysts. ACS Nano, 2015, 9, 9322-9330.

${ }^{77}$ Dubois, J.-L.; Sayama, K.; Arakawa, H. $\mathrm{CO}_{2}$ Hydrogenation over Carbide Catalysts. Chem. Lett. 1992, 21, 5-8.

${ }^{78}$ Hwu, H.; Chen, J.G. Surface Chemistry of Transition Metal Carbides. Chem. Rev. 2005, 105, $185-212$

79 Toulhoat, H.; Raybaud, P. Catalysis by Transition Metal Sulphides; Editions Technip: Paris, 2013.

80 Jaramillo, T. F.; Jørgensen, K. P.; Bonde, J.; Nielsen, J. H.; Horch, S.; Chorkendorff, I. Identification of Active Edge Sites for Electrochemical $\mathrm{H}_{2}$ Evolution from $\mathrm{MoS}_{2}$ Nanocatalysts. Science 2007, 317, 100-102

${ }^{81}$ Lauritsen, J. V.; Bollinger, M. V.; Lægsgaard, E.; Jacobsen, K. W.; Nørskov, J. K.; Clausen, B. S.; Topsøe, H.; Besenbacher, F. Atomic-Scale Insight into Structure and Morphology Changes of $\mathrm{MoS}_{2}$ Nanoclusters in Hydrotreating Catalysts. J. Catal. 2004, 221, 510-522. 


\section{Figure Captions}

Figure 1. Scheme for the preparation of an inverse $\mathrm{TiO}_{\mathrm{x}} / \mathrm{Au}$ catalyst by atomic layer deposition (ALD). Taken from ref. 7. Copyright 2016 American Chemical Society.

Figure 2. A) HR-TEM image for a $\mathrm{Cu} / \mathrm{ZnO} / \mathrm{Al}_{2} \mathrm{O}_{3}$ catalyst after reduction in hydrogen. B) Cartoon showing different components of a reduced $\mathrm{Cu} / \mathrm{ZnO} / \mathrm{Al}_{2} \mathrm{O}_{3}$ catalysts. Taken from ref. 21. Copyright 2015 Wiley.

Figure $3 \mathrm{CO}_{2}$ production measured over $\mathrm{ZnO}$ films on $\mathrm{Pt}(111)$ as a function of the nominal film thickness. The inset shows kinetic curves for the production of $\mathrm{CO}_{2}$ on pure $\operatorname{Pt}(111)$ and on 0.7 ML $\mathrm{ZnO} / \mathrm{Pt}(111)$. Reaction conditions: $10 \mathrm{mbar}$ of $\mathrm{CO}$ and $50 \mathrm{mbar}$ of $\mathrm{O}_{2}$, He balance to 1 bar; temperature of $450 \mathrm{~K}$. Taken from ref. 13. Copyright 2013 Elsevier.

Figure 4 STM images of (a) FeO, (b) Fe3O4 and (c) Fe2O3 nanostructures on $\mathrm{Au}(111)$. The corresponding apparent heights of these nanostructures, as marked by white lines in STM images are plotted on the right side of the STM image, respectively. Inset of each STM image shows the atomic resolution of nanostructures. Taken from ref. 32. Copyright 2015 American Chemical Society.

Figure 5 Phase diagram of iron species on $\mathrm{Au}(111)$ with morphology of (a) nanostructures and (b) bulk structures for $\mathrm{FeO}_{\mathrm{x}}$ under the $\mathrm{CO}$ oxidation conditions at $575 \mathrm{~K}$. The squares denote the pressure range of interest $\left(10^{-5} \sim 1 \mathrm{~atm}\right)$ of $\mathrm{CO}$ and $\mathrm{O}_{2}$ for $\mathrm{CO}$ oxidation. Taken from ref. 32 . Copyright 2015 American Chemical Society.

Figure 6 DFT calculations of the $\mathrm{FeO}$ oxidation on $\mathrm{Au}(111)$ and $\mathrm{Pt}(111)$ surfaces. (a) $\mathrm{Fe}_{10} \mathrm{O}_{6}$ (top panel) and $\mathrm{Fe}_{10} \mathrm{O}_{18}$ (bottom panel) structures on $\mathrm{Pt}(111)$ surface. (b) Energy scheme for structural transformation of metastable $\mathrm{Fe}_{10} \mathrm{O}_{6}$ structure to the stable $\mathrm{Fe}_{10} \mathrm{O}_{18}$ structure on $\mathrm{Au}(111)$ and $\mathrm{Pt}(111)$ surfaces, $\mathrm{Fe}_{10} \mathrm{O}_{6}+6 \mathrm{O}_{2} \rightarrow \mathrm{Fe}_{10} \mathrm{O}_{18}$. The metal surface exerts a confinement effect on the surface oxide, lowering the energy of $\mathrm{Fe}_{10} \mathrm{O}_{18}$, which is termed as interface 
confinement effect $\left(\mathrm{E}_{\text {confinement }}\right)$. Taken from ref. 31. Copyright 2015 American Chemical Society.

Figure 7 Close-up view of a $\mathrm{CeO}_{2-\mathrm{x}}$ island on $\mathrm{Au}(111)$. The black regions inside the island denote clusters of O vacancies. Taken from ref. 55. Copyright 2007 Elsevier.

Figure 8 A comparison of the structure in real (LEEM and STM, all $200 \times 200 \mathrm{~nm}^{2}$ ) and reciprocal (LEED) space of inverse ceria nanostructures on various metal substrates. ${ }^{34,43,45,50,54,55,56}$ To generate these systems, Ce was usually dosed to the metal substrates under an atmosphere of oxygen. The lattice spacing for the substrates are stated, along with the ratio relative to the $\mathrm{CeO}_{2}(111)$ surface. Clear variations in the morphology of the ceria islands are evident. The red solid and blue dashed circles highlight the first order diffraction spots from the substrate and ceria, respectively. The LEED patterns were acquired at different energies.

Figure 9 Optimized structures for $\mathrm{CeO}_{\mathrm{x}} / \mathrm{M}(111)$ systems. $\mathrm{CeO}_{\mathrm{x}} / \mathrm{Cu}(111)$ (left), $\mathrm{CeO}_{\mathrm{x}} / \mathrm{Ag}(111)$ (middle), and $\mathrm{CeO}_{\mathrm{x}} / \mathrm{Au}(111)$ (right). Top view (top), side view (bottom). Cerium (white), oxygen (red), copper (orange), silver (soft gray), and gold (golden). Taken from ref. 39. Copyright 2014 American Chemical Society.

Figure 10 Top: STM images for 0.3 (a) and 0.7 (b) monolayers of $\mathrm{CeO}_{x}$ on $\operatorname{Pt}(111)$. Bottom: Data for CO oxidation. (c) Comparison of the hysteresis loops obtained for the clean $\operatorname{Pt}(111)$ surface and for the $\mathrm{CeO} x-0.3 \mathrm{ML} / \mathrm{Pt}(111)$ and $\mathrm{CeO} x-0.7 \mathrm{ML} / \mathrm{Pt}(111)$ systems at $T=453 \mathrm{~K}$ and $p_{\mathrm{O} 2}=1.3 \times 10-5$ mbar. The maximum in the $\mathrm{CO}_{2}$ production rate, $R_{\mathrm{CO} 2}$, is used as a measure of the catalytic activity of the corresponding system for comparison in (d). (d) Comparison of the catalytic activity of the clean $\mathrm{Pt}(111), \mathrm{CeO} x-0.3 / \mathrm{Pt}(111)$ and $\mathrm{CeO} x-0.7 / \mathrm{Pt}(111)$ systems toward $\mathrm{CO}$ oxidation. Left side bars: total activity; right side bars: activity normalized by the exposed (bare) Pt(111) surface. Taken from ref. 15. Copyright 2008 American Chemical Society.

Figure 11 a) Arrhenius plots of the water-gas shift rate (CO: 20 Torr, $\mathrm{H}_{2} \mathrm{O}: 10$ Torr) on clean $\mathrm{Cu}(111), \mathrm{CeOx} / \mathrm{Cu}(111)$, and $\mathrm{CeOx} / \mathrm{Au}(111)$. b) STM image for a $\mathrm{CeO}_{\mathrm{x}} / \mathrm{CuO}_{\mathrm{x}} / \mathrm{Cu}(111)$ before exposure to a $\mathrm{CO} / \mathrm{H}_{2} \mathrm{O}$ reaction mixture. $\mathrm{c}$ and d) Calculated reaction mechanism for the watergas shift on $\mathrm{CeO}_{\mathrm{x}} / \mathrm{Cu}(111)$. Taken from ref. 60. Copyright 2013 Wiley. 
Figure 12 A) Rate for the conversion of $\mathrm{CO}_{2}$ to methanol on $\mathrm{Cu}(111)$ as a function of the fraction of the metal surface covered by zinc oxide or ceria. Reaction conditions: $\mathrm{T}=550 \mathrm{~K}, \mathrm{P}_{\mathrm{H} 2}=$ $4.5 \mathrm{~atm}, \mathrm{P}_{\mathrm{CO} 2}=0.5 \mathrm{~atm}$. B) Arrhenius plots for the conversion of $\mathrm{CO}_{2}$ to methanol on plain $\mathrm{Cu}(111)$ and on the metal surface covered $20 \%$ by nanoparticles of $\mathrm{ZnO}$ or $\mathrm{Ce}_{2} \mathrm{O}_{3}$. Reaction conditions: $\mathrm{P}_{\mathrm{H} 2}=4.5$ atm, $\mathrm{P}_{\mathrm{CO} 2}=0.5$ atm. Taken from ref. 34. Copyright 2016 American Chemical Society.

Figure 13 Rates measured for the production of metanol on $\mathrm{Cu}(111), \mathrm{Cu} / \mathrm{ZnO}(000 \overline{1})$, $\mathrm{ZnO} / \mathrm{Cu}(111), \mathrm{Cu} / \mathrm{CeO}_{2}(111)$ and $\mathrm{CeO}_{\mathrm{x}} / \mathrm{Cu}(111)$. Reaction conditions: $\mathrm{T}=550 \mathrm{~K}, \mathrm{P}_{\mathrm{H} 2}=4.5$ atm, $\mathrm{P}_{\mathrm{CO} 2}=0.5$ atm. Taken from ref. 34. Copyright 2016 American Chemical Society.

Figure 14 Left-side: HR-TEM images of unsupported Au nanocrystals with 20 cycles of $\mathrm{TiO}_{2}$ overcoat at low (a) and high (b) magnifications. Here $\mathrm{TiO}_{2}$ islands formed on the $\mathrm{Au}$ nanocrystals are highlighted by the black arrows. Right-side: (c) (a) Catalytic activities of $\mathrm{Au} / \mathrm{Al}_{2} \mathrm{O}_{3}$ catalysts with different cycles of $\mathrm{TiO}_{2} \mathrm{ALD}$ overcoat $\left(\mathrm{xc}-\mathrm{Au} / \mathrm{Al}_{2} \mathrm{O}_{3}\right.$ ) in $\mathrm{CO}$ oxidation reaction. Taken from ref. 7. Copyright 2016 American Chemical Society.

Figure 15 Top: HR-TEM investigation of $\mathrm{TiO}_{2} / \mathrm{np}$-Au catalysts. (a) A cross-sectional HR-TEM image of a 0.1 weight $\%$ TTIP-impregnated $\mathrm{TiO}_{2} / \mathrm{np}$-Au catalyst showing the lattice images of $\mathrm{Au}$ and $\mathrm{TiO}_{2}$ (scale bar refers to $1 \mathrm{~nm}$ ). (b) A cross-sectional HR-TEM image of a 1.0 weight\% TTIP-impregnated $\mathrm{TiO}_{2} / \mathrm{np}$-Au film catalyst. The inset shows a lattice image of the Au (scale bar refers to $2 \mathrm{~nm}$ ). Bottom: (c) Summary of the TOF for all $\mathrm{TiO}_{2} / \mathrm{np}$-Au catalysts at $443 \mathrm{~K}$ under $\mathrm{H}_{2}$ oxidation. The TOF increased 4-fold for the 0.5 weight $\%$ TTIPimpregnated $\mathrm{TiO}_{2} / \mathrm{np}$-Au catalysts in relation to the bare np-Au film. (d) A schematic representation of catalytic $\mathrm{H}_{2}$ oxidation at the $\mathrm{TiO}_{2} / \mathrm{np}$-Au perimeter interface created between the nanoporous Au ligament and the deposited titania layers. Hydrogen molecules adsorb on the np-Au perimeter sites, followed by dissociation and spilling to the titania; gaseous $\mathrm{O}_{2}$ molecules adsorbed on the titania perimeter sites form $\mathrm{Ti}-$ $\mathrm{OOH}$ species that dissociate into $\mathrm{Ti}-\mathrm{O}$ and $\mathrm{Ti}-\mathrm{OH}$ species. The $\mathrm{Ti}-\mathrm{OH}$ species finally hydrogenate to form $\mathrm{H}_{2} \mathrm{O}$ molecules. Taken from ref. 6. Copyright 2015 Royal Society of Chemistry. 
Figure 16 Left side: Cartoon illustrating the migration of $\mathrm{ZnO}_{\mathrm{x}}$ agregates to the top of $\mathrm{Cu}$ particles in $\mathrm{Cu} / \mathrm{ZnO}$ and $\mathrm{Cu} / \mathrm{ZnO}: \mathrm{M}$ catalysts $\left(\mathrm{M}=\mathrm{Al}^{3+}\right.$ and $\left.\mathrm{Ga}^{3+}\right)$. Such migration is not observed for the $\mathrm{Cu} / \mathrm{ZnO}: \mathrm{Mg}$ catalyst. Right side: Activity, weight time yield, of $\mathrm{Cu} / \mathrm{ZnO}$ and $\mathrm{Cu} / \mathrm{ZnO}: \mathrm{M}$ catalysts for methanol synthesis. Reproduced from ref. 22, Copyright 2015 American Chemical Society.

Figure 17 (a) STM image of $\mathrm{MoS}_{2}$ nanoparticles synthesized on the $\mathrm{Au}(111)$ substrate at 0.15 ML coverage and (b) A close-up of a Mo edge terminated $\mathrm{MoS}_{2}$ cluster compared to the corresponding STM image simulated by means of DFT and the Tersoff-Hamann approximation. Taken from ref. 72. Copyright 2015 American Chemical Society (c) STM image for a nanoparticle of $\mathrm{RuS}_{2}$ synthesized on $\mathrm{Au}(111)$. Taken from ref. 73. Copyright 2004 American Chemical Society 

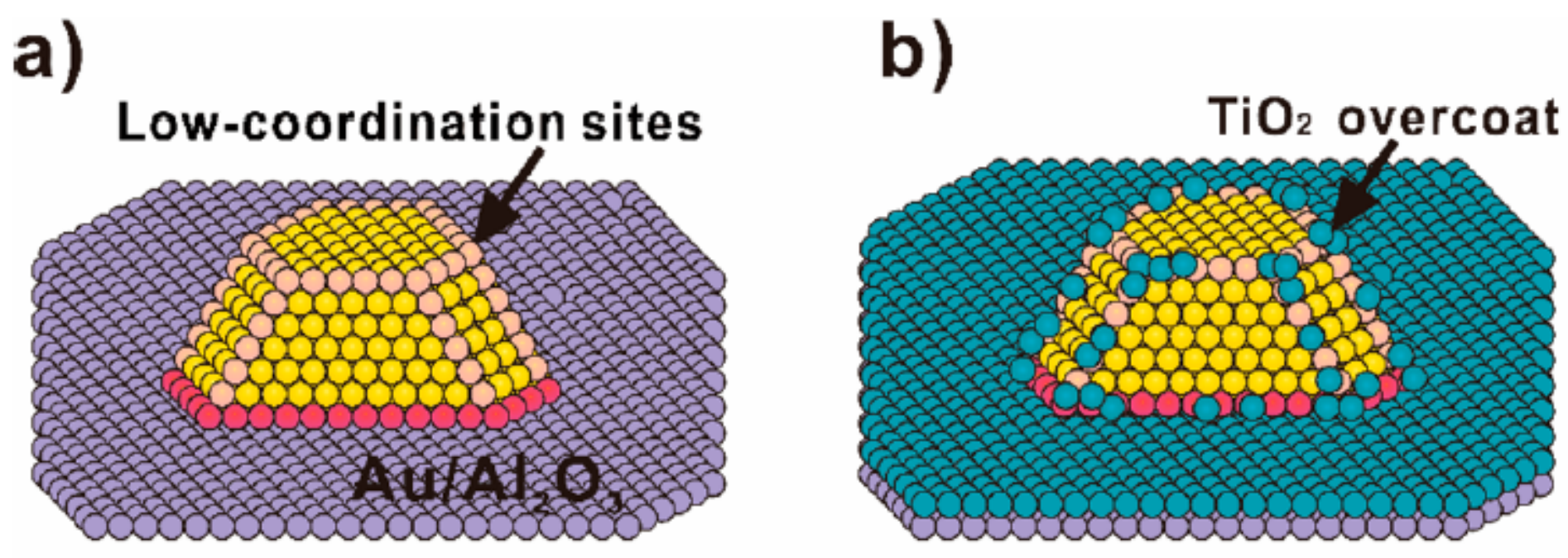

$\mathrm{TiO}_{2}$ ALD

$\mathrm{TiO}_{2} / \mathrm{Au}$ inverse catalyst

Figure 1 

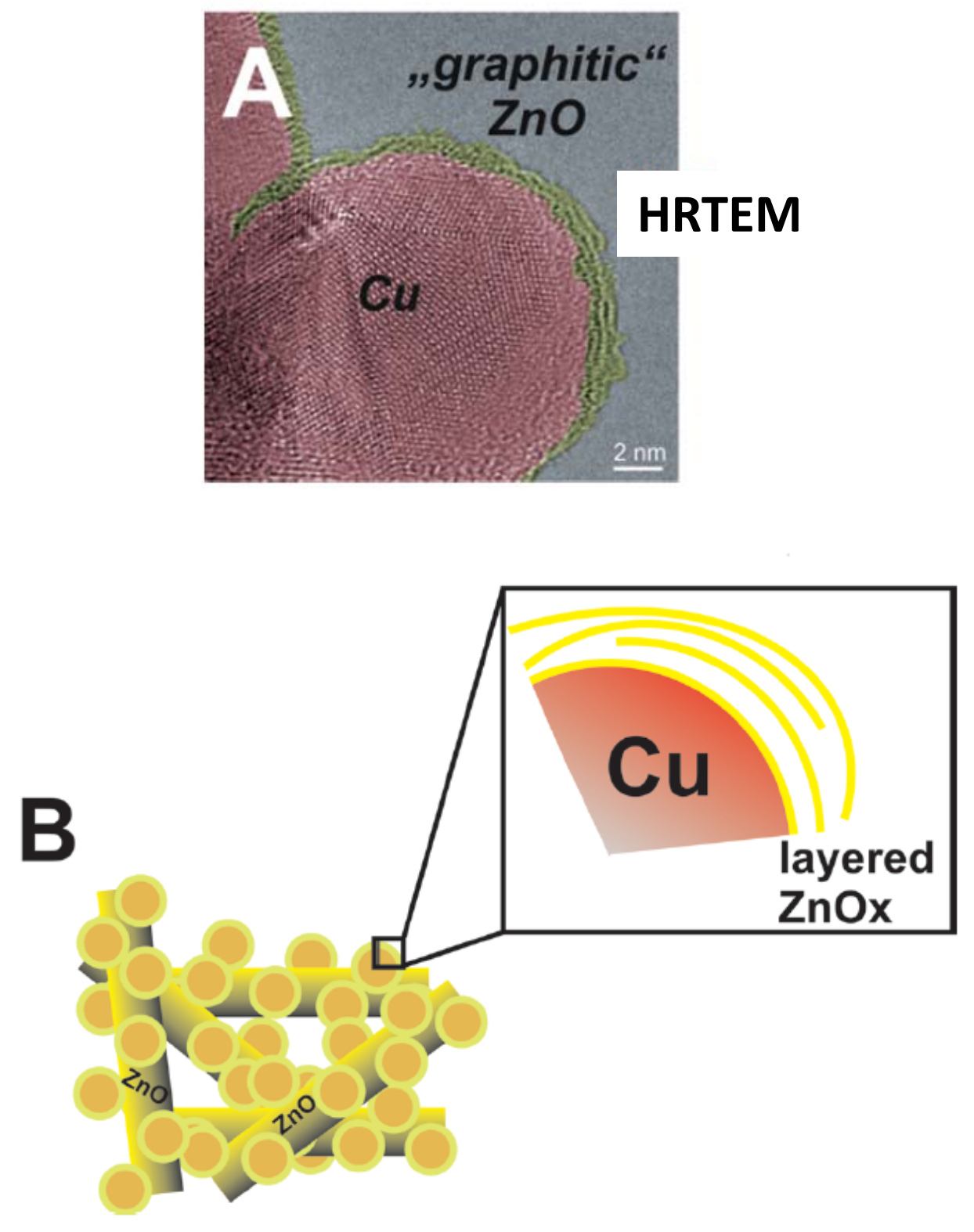

Figure 2 


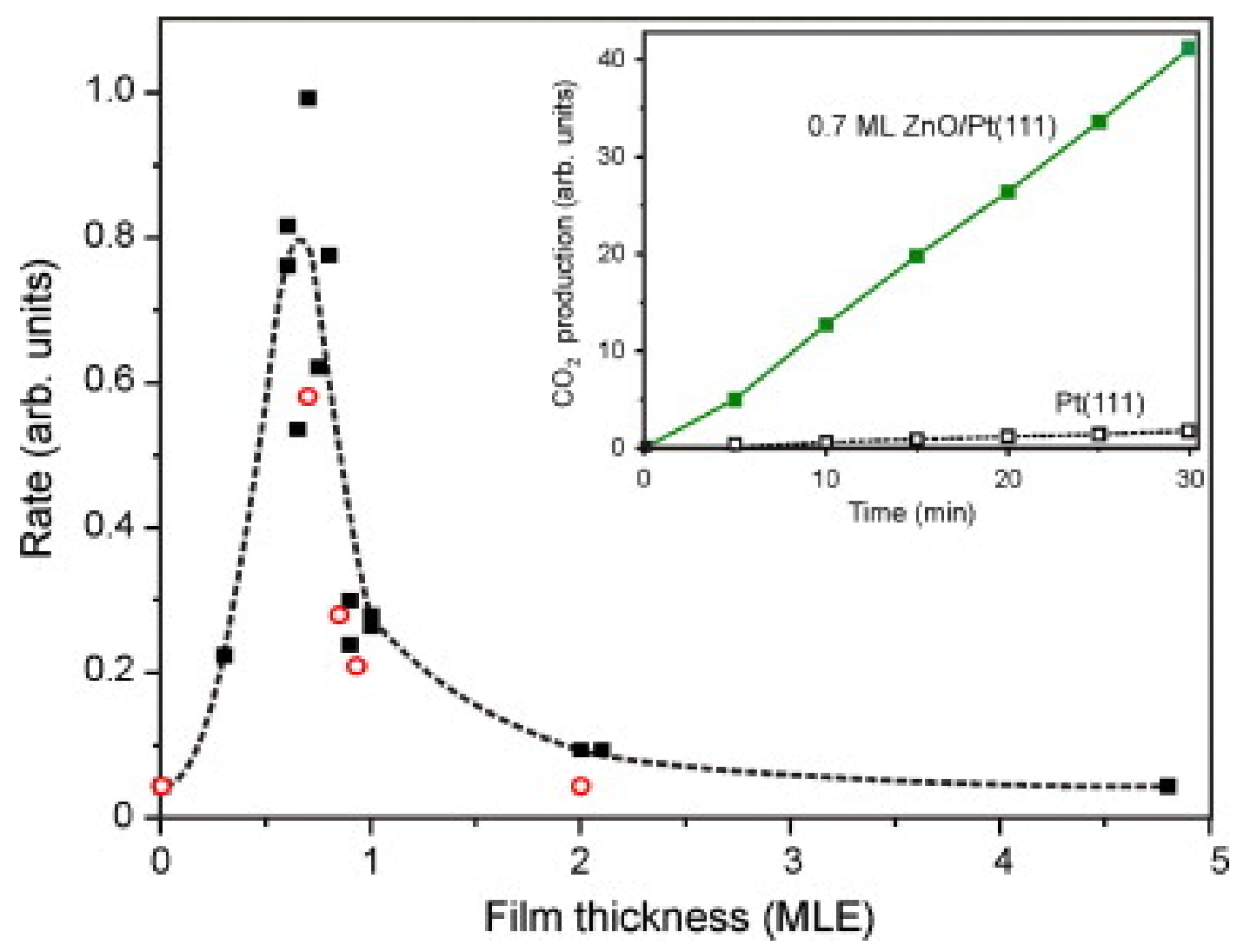

Figure 3 

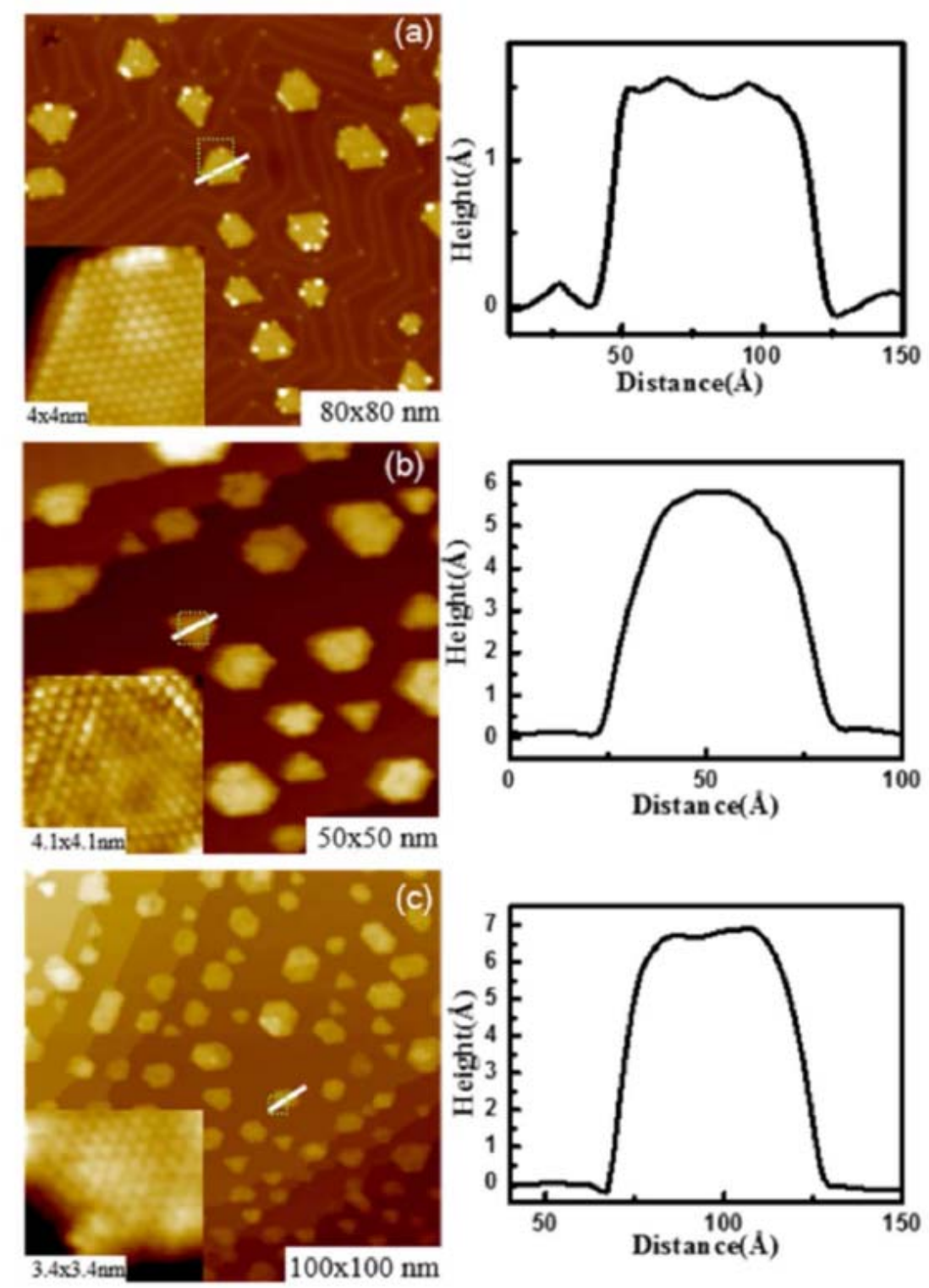

Figure 4 

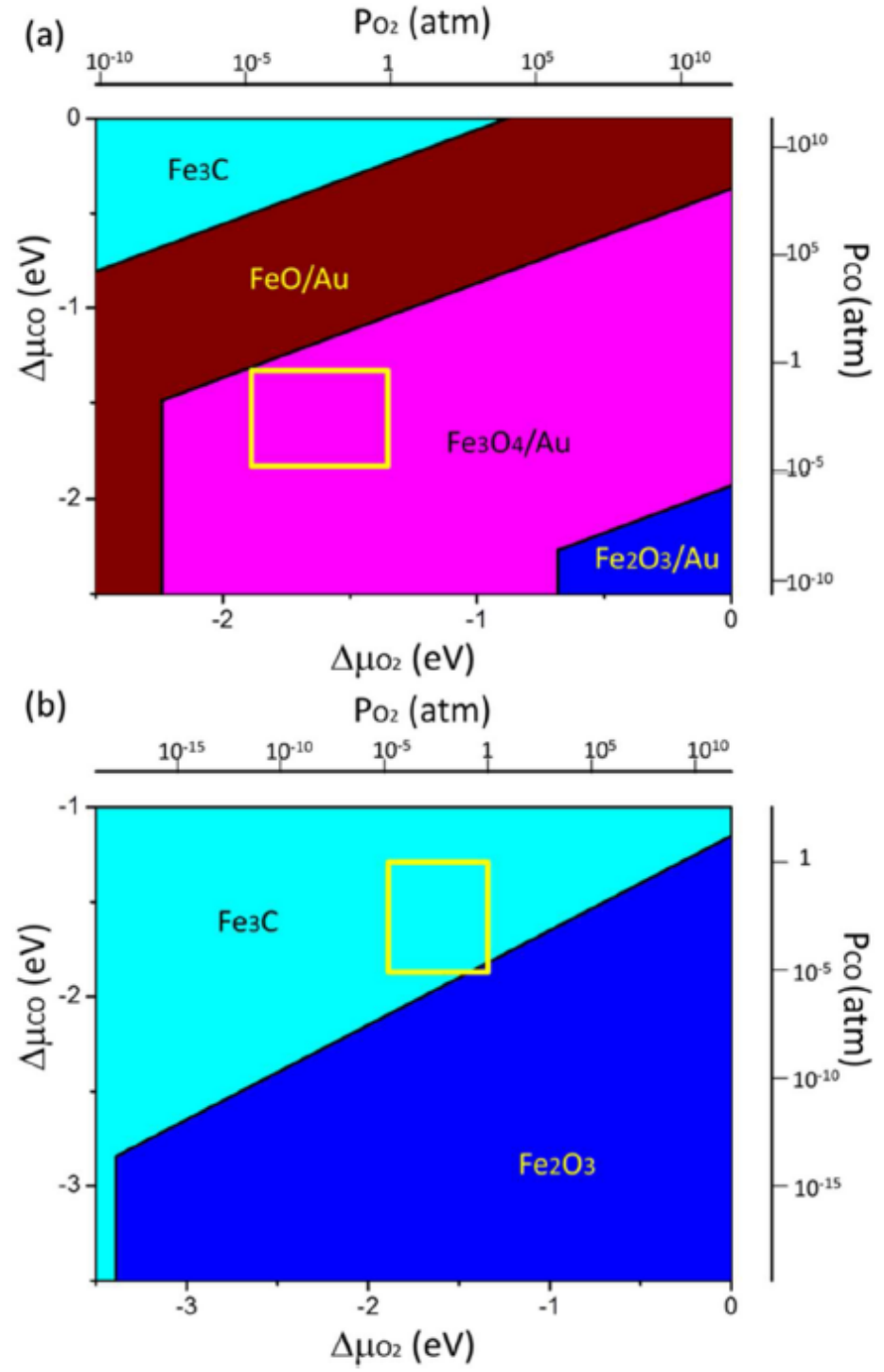

Figure 5 

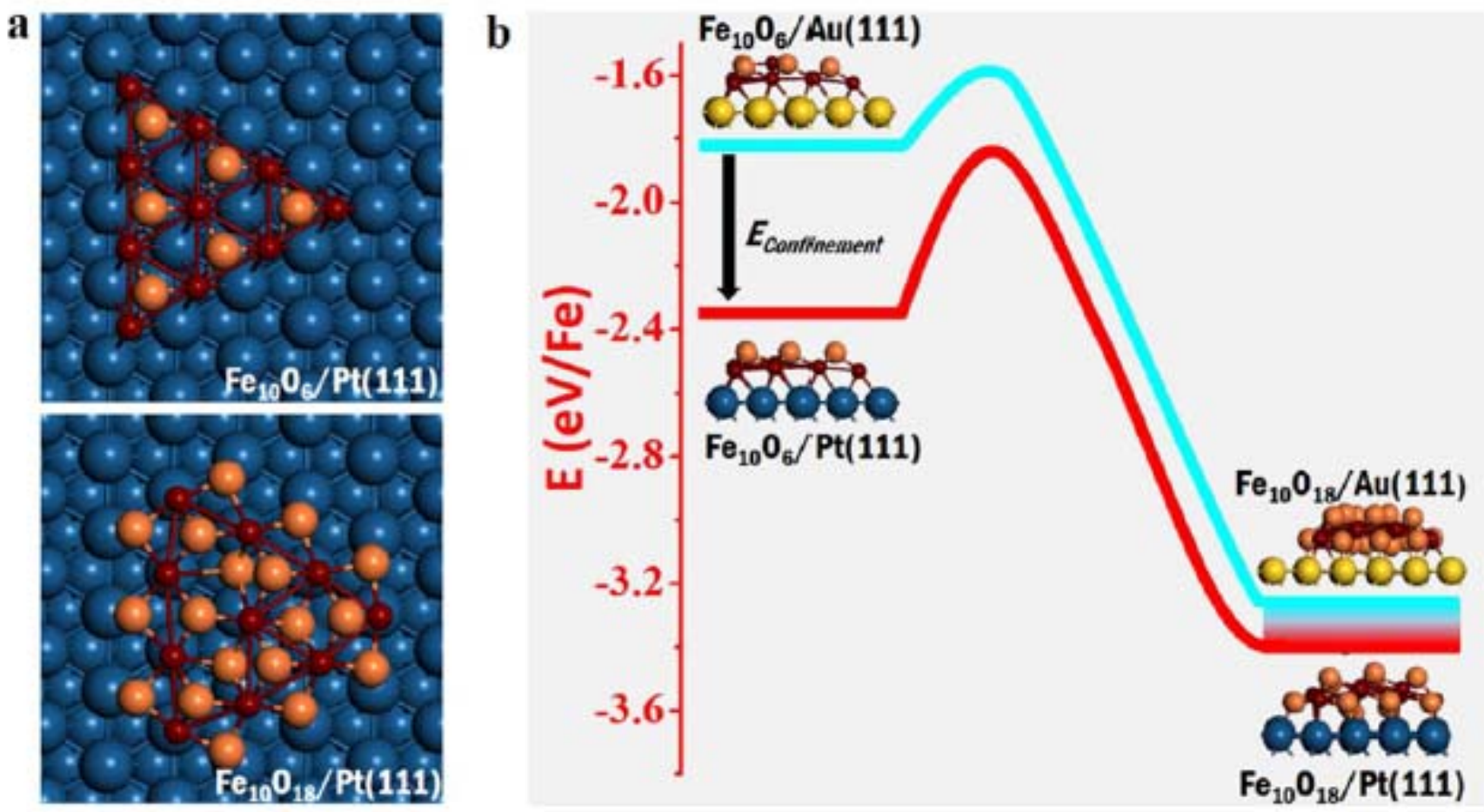

Figure 6 


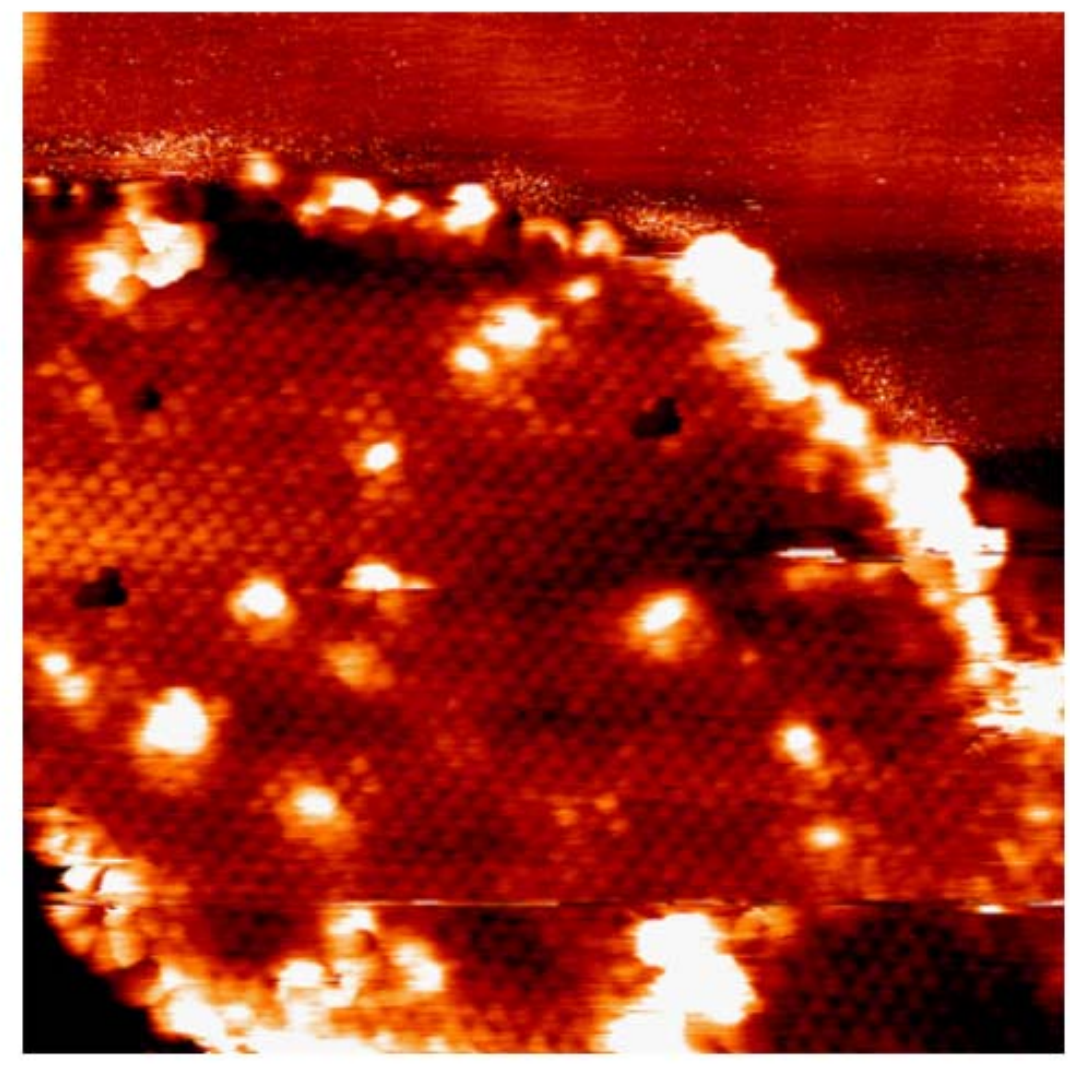

$15 \mathrm{~nm} \times 15 \mathrm{~nm}$

Figure 7 

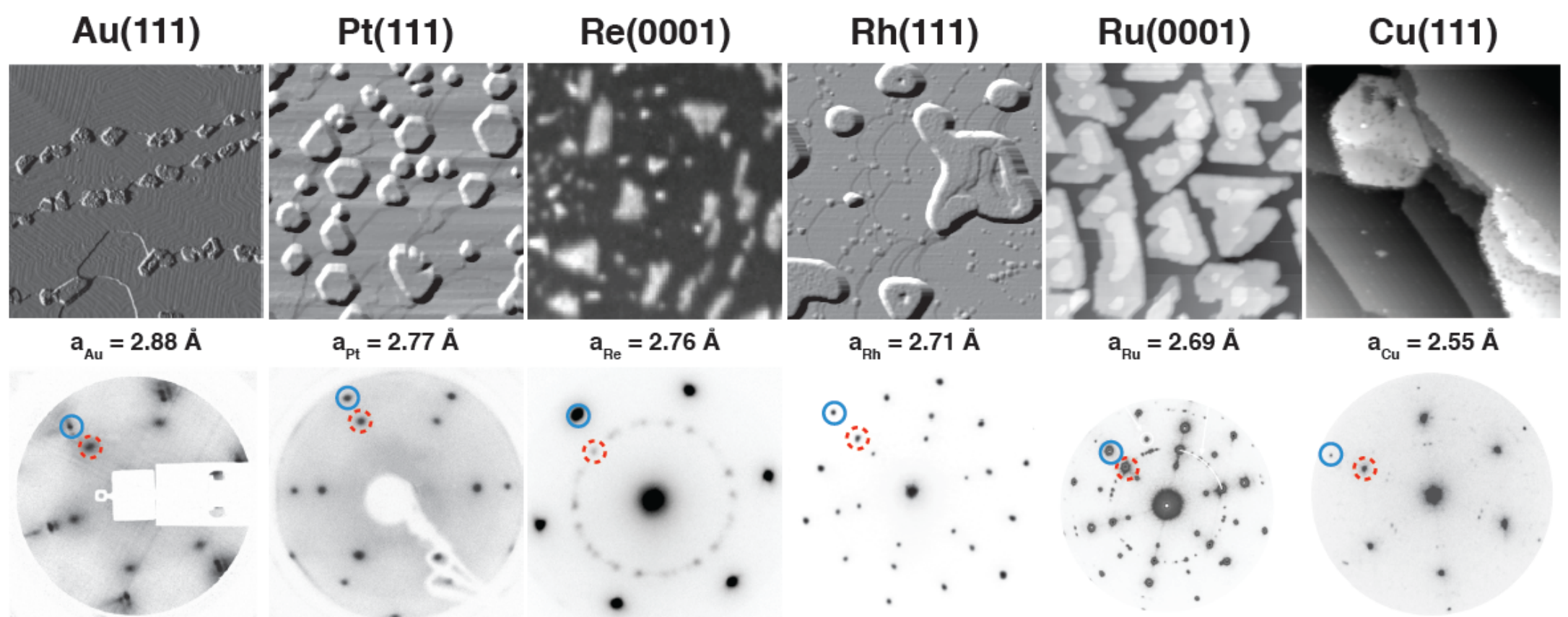

1:1.33

$1: 1.38$

$1: 1.39$

1:1.41

1:1.42

$1: 1.43$

$\mathrm{a}_{\mathrm{CeO} 2}=3.83 \AA$

Figure 8 

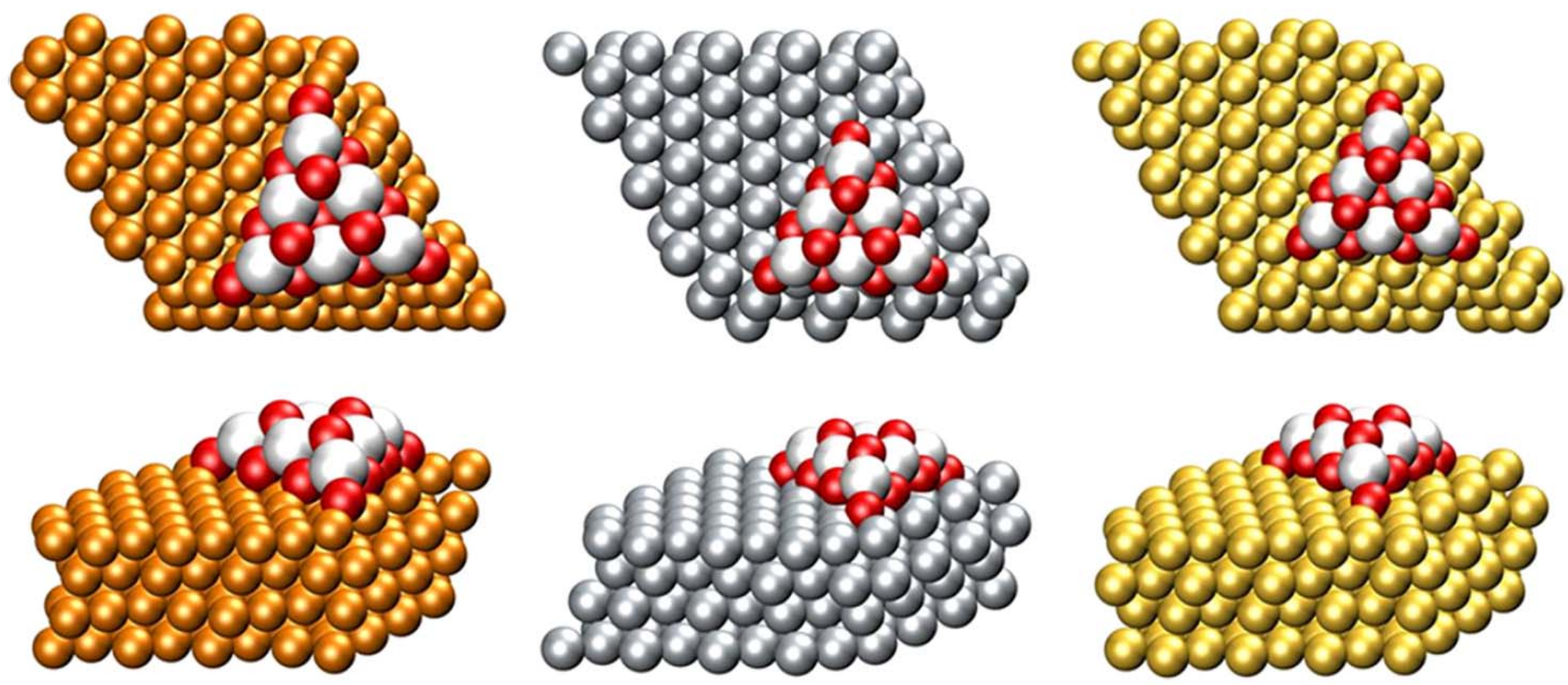

Figure 9 

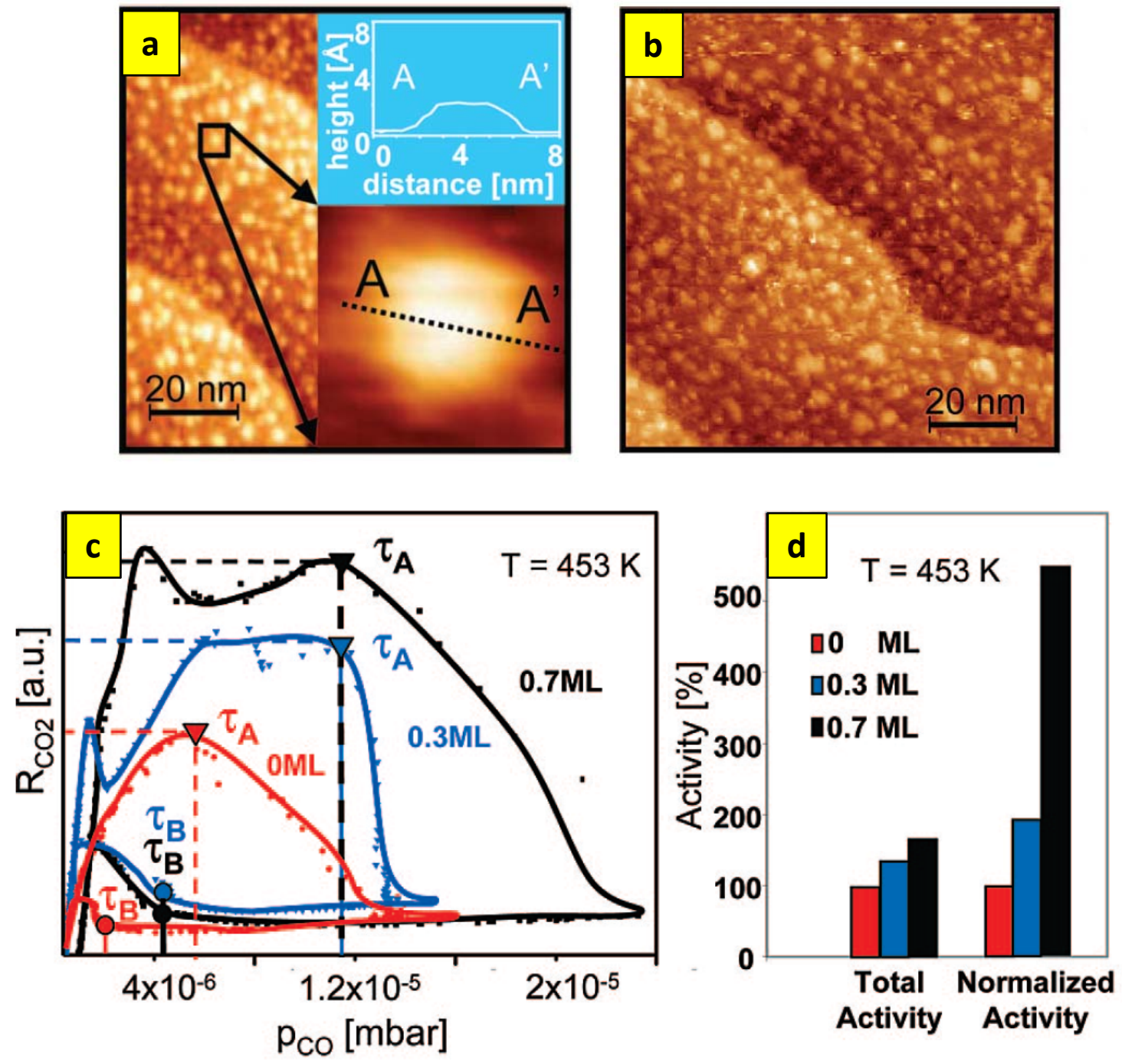

Figure 10 

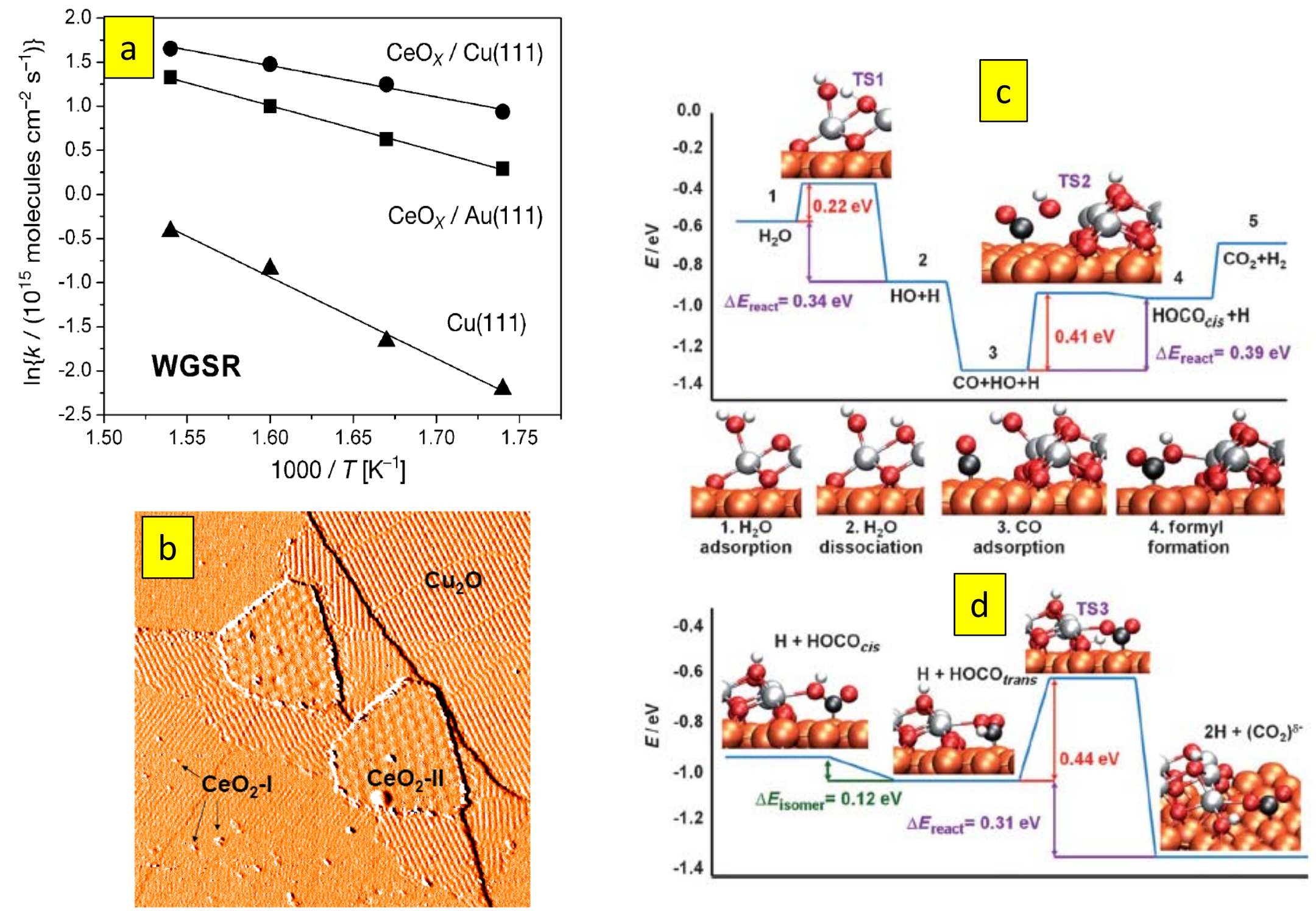

$150 \mathrm{~nm} \times 150 \mathrm{~nm}$

Figure 11 

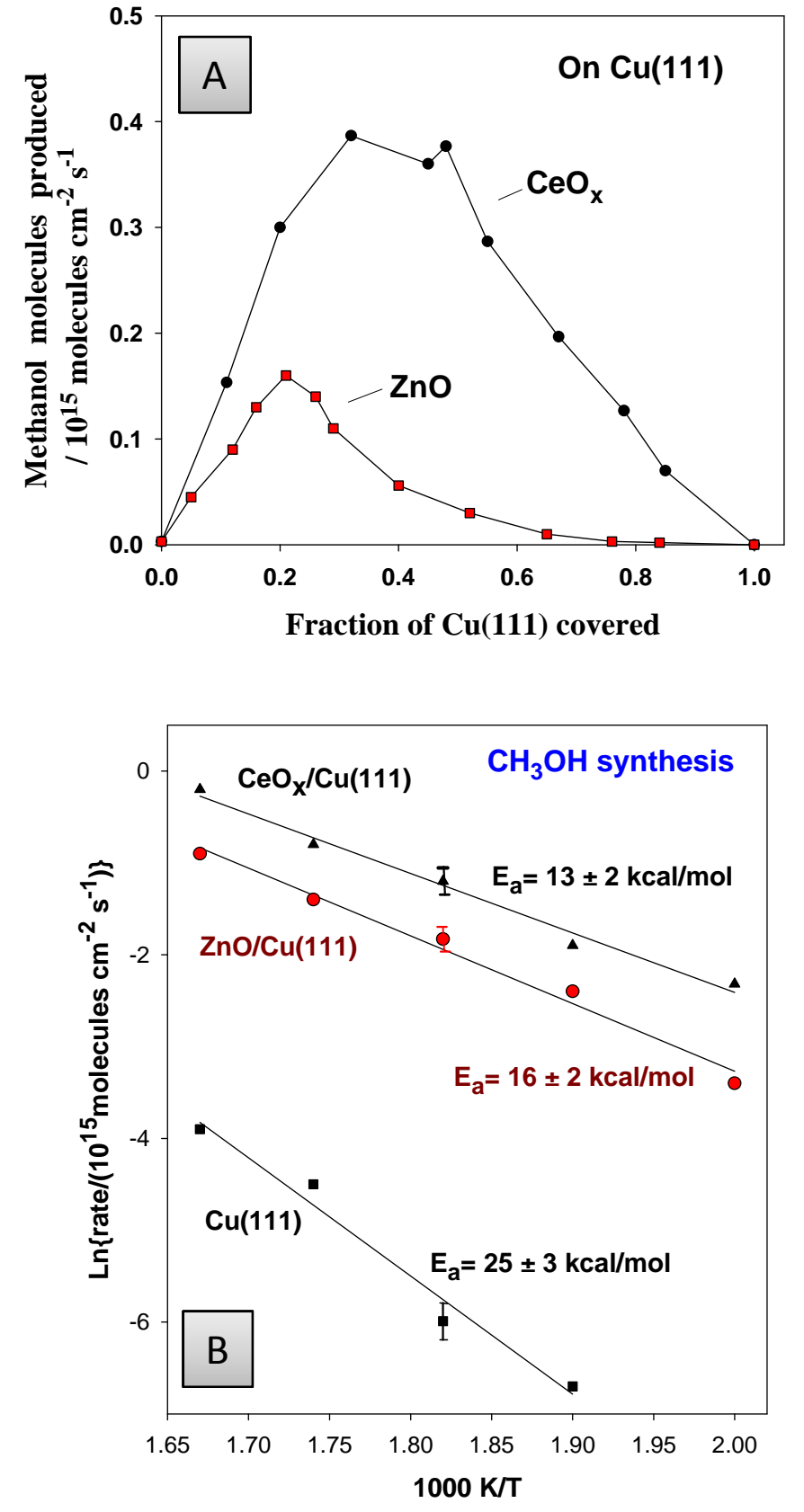

Figure 12 


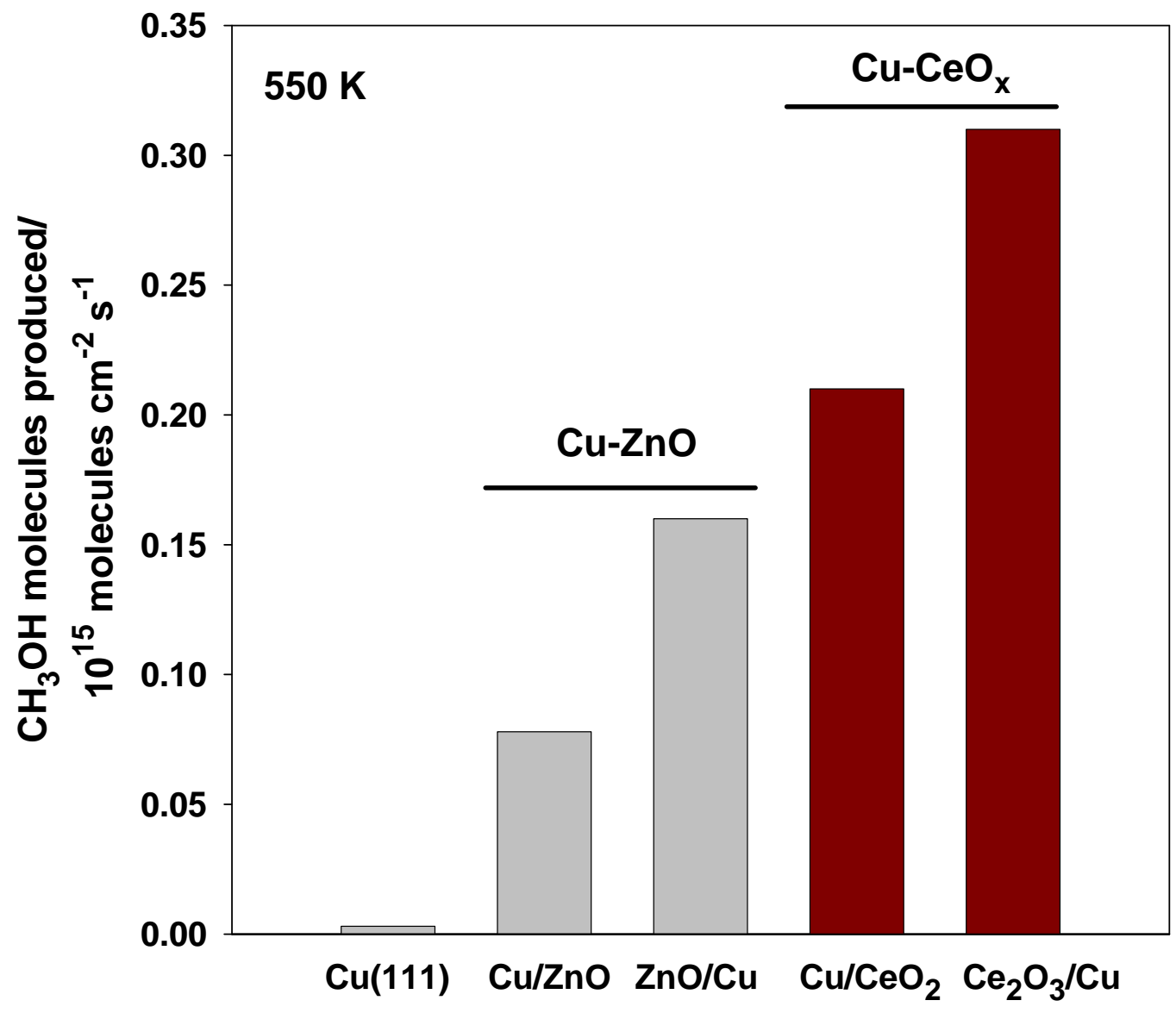

Figure 13 

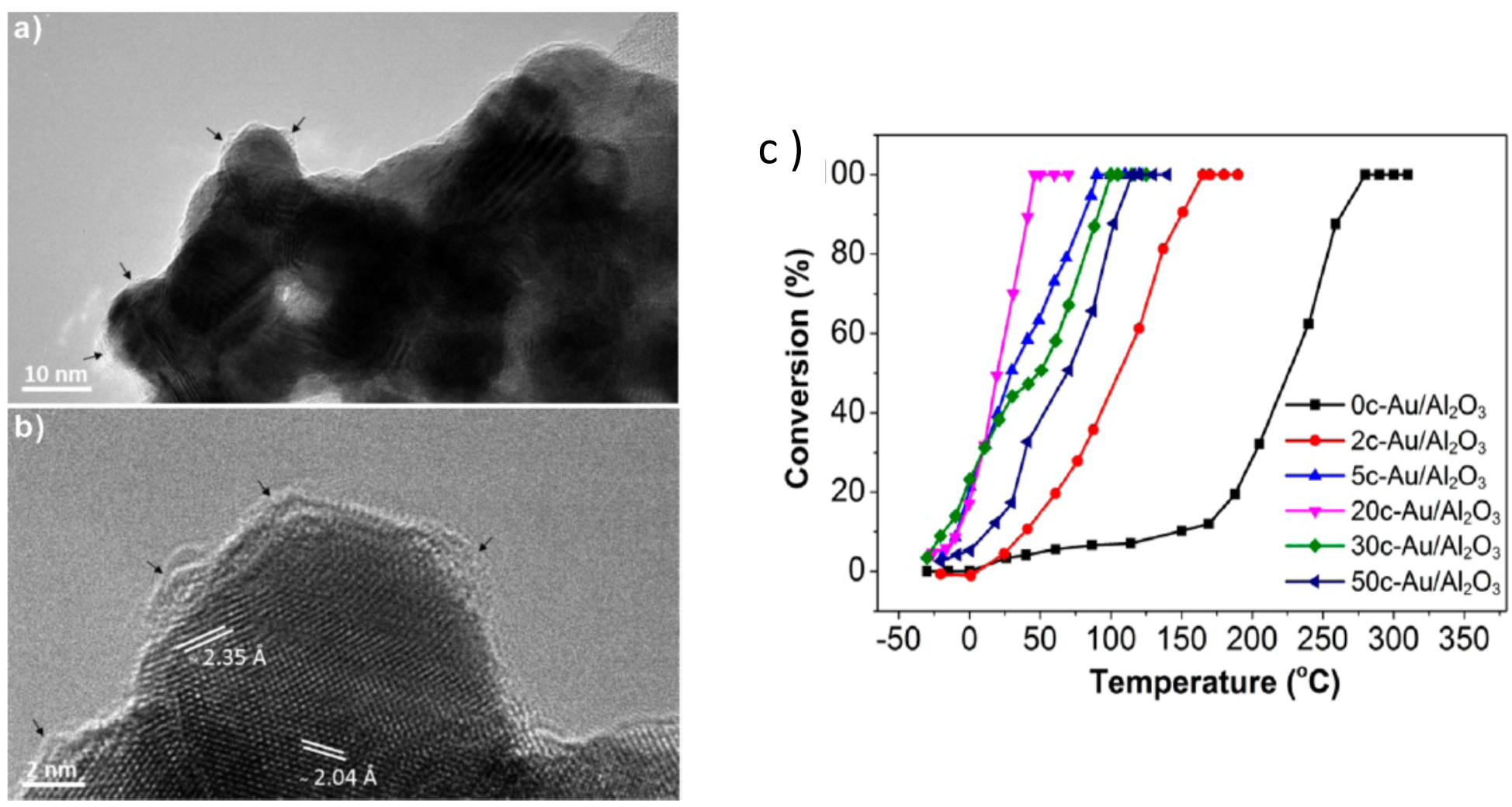

Figure 14 
(a)

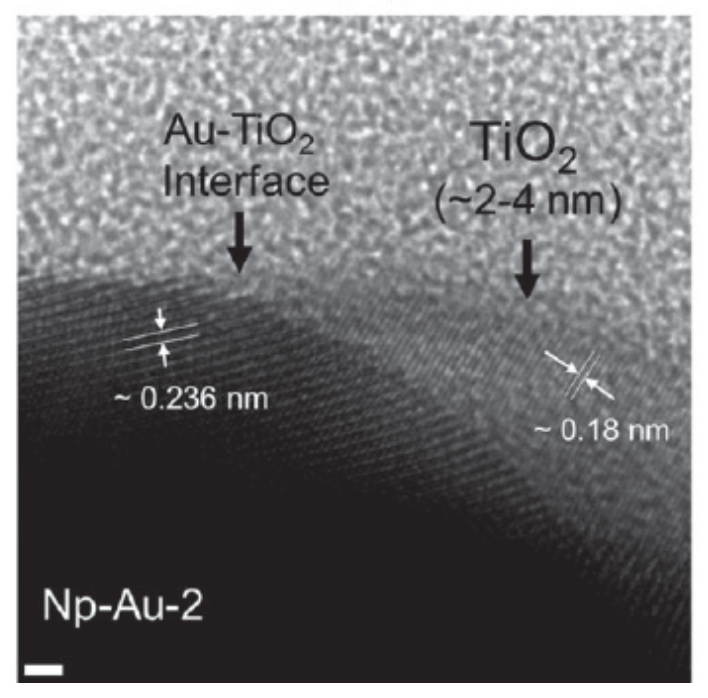

(c)

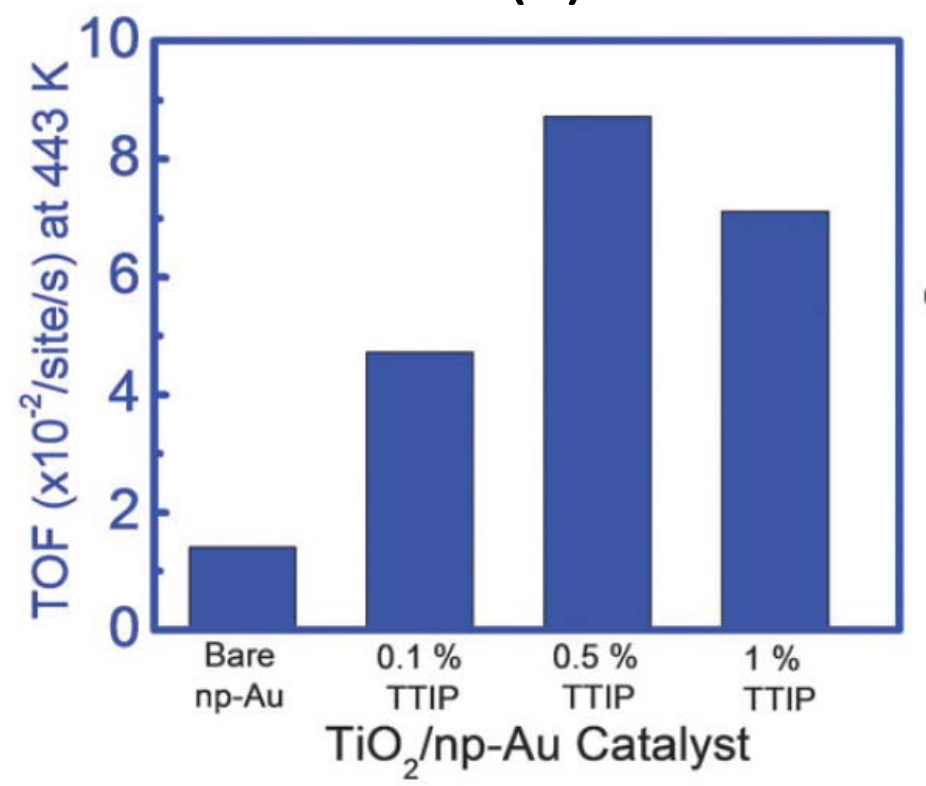

(b)

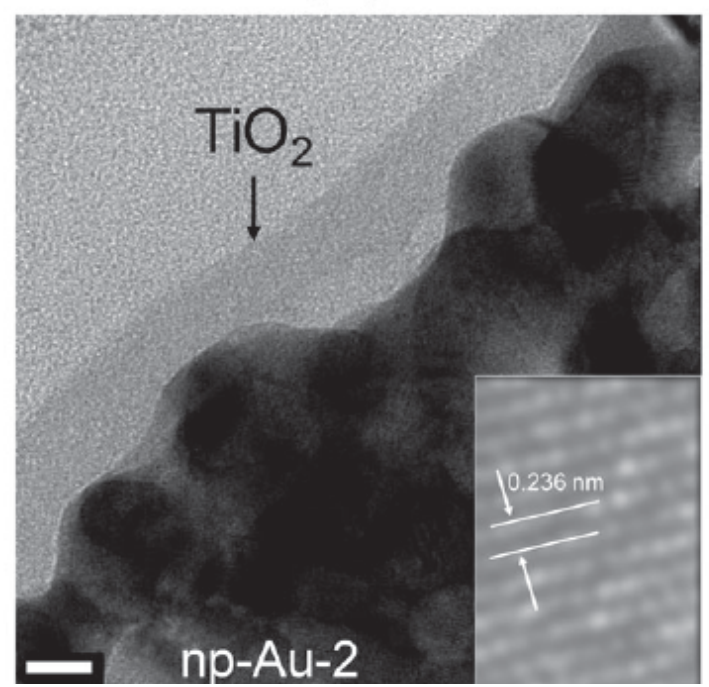

(d)

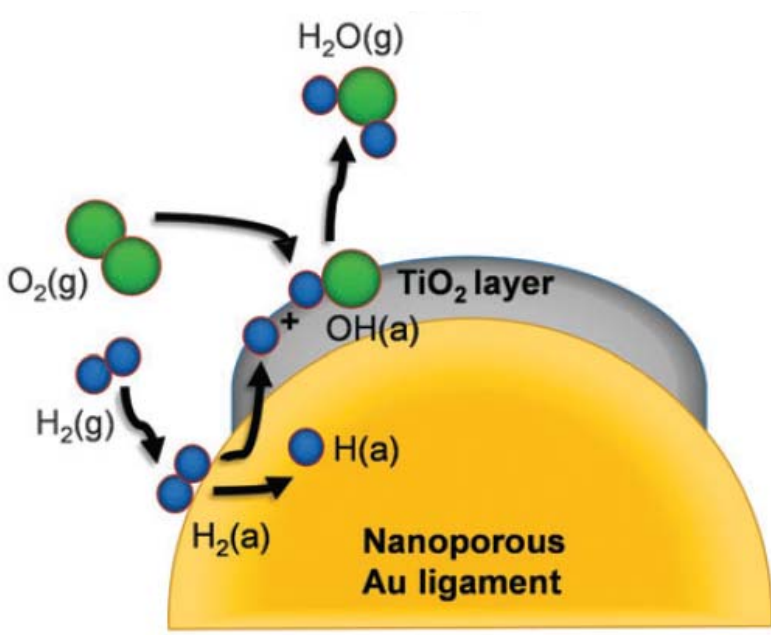

Figure 15 


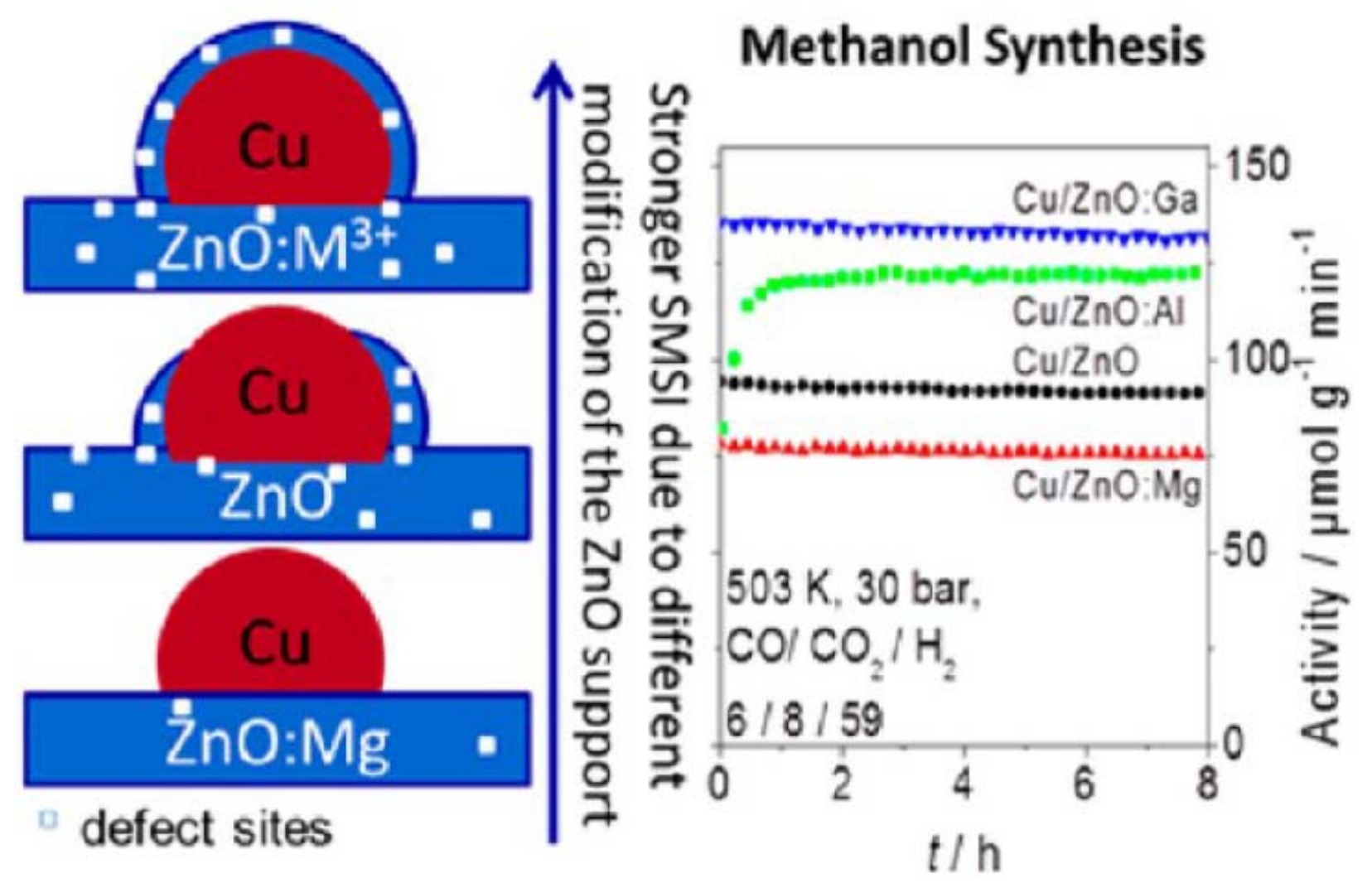

Figure 16 

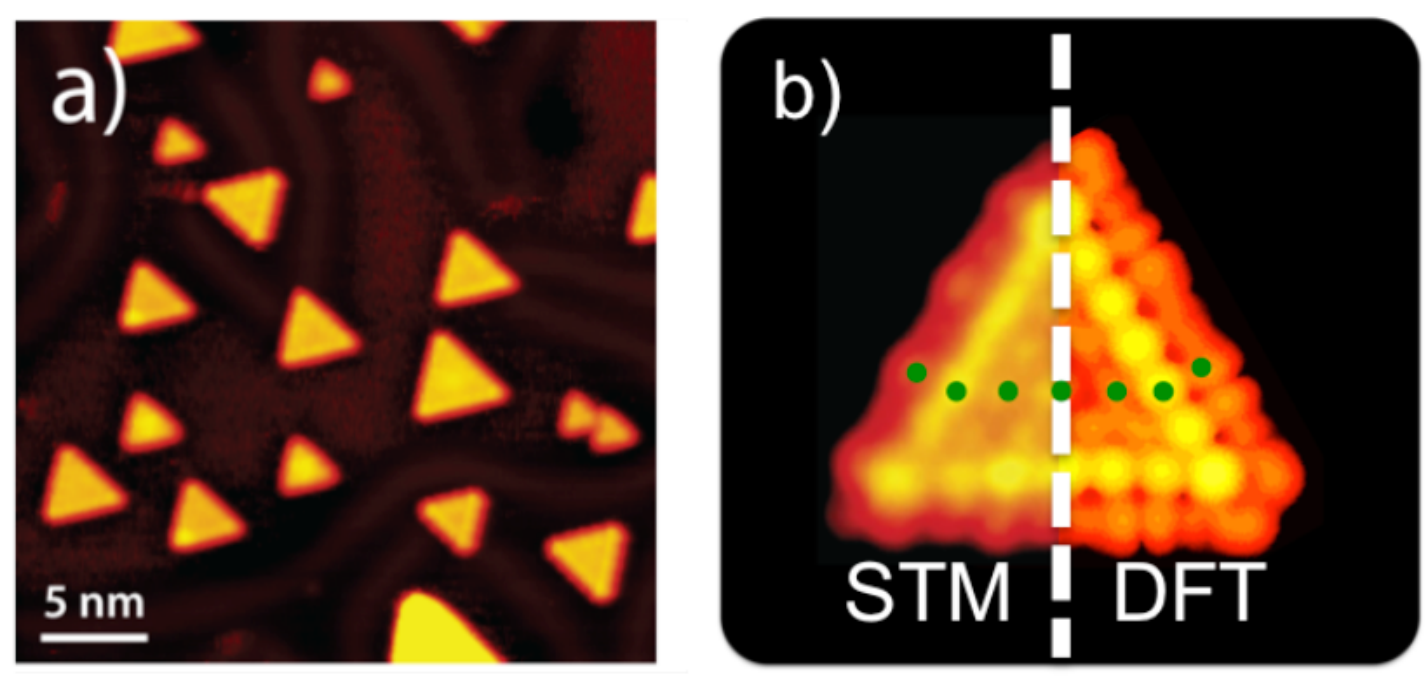

\section{$\mathrm{MoS}_{2} / \mathrm{Au}(111)$}

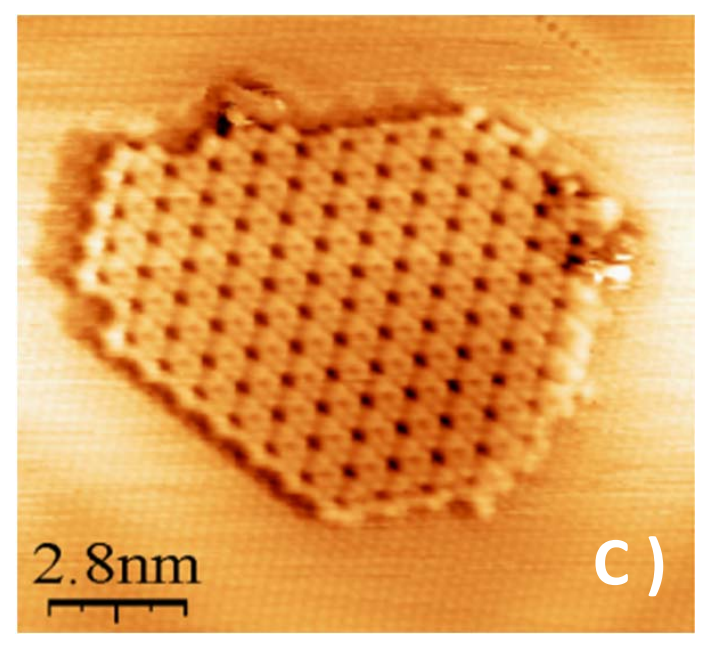

$\mathrm{RuS}_{2} / \mathrm{Au}(111)$ 